\title{
AN EXPERIMENTAL STUDY OF THE IMPACT OF LOCATION ON THE EFFECTIVENESS OF RECRUITMENT CLUSTERS FOR RED-COCKADED WOODPECKERS AT THE SAVANNAH RIVER SITE
}

\section{PROJECT FINAL REPORT}

\author{
Submitted By: \\ Jeffrey R. Walters \\ Department of Biological Sciences, Virginia Polytechnic Institute and State University \\ Peter A. Johnston \\ USDA Forest Service, Savannah River \\ And \\ Larry B. Crowder and Jeffery A. Priddy \\ Duke University Marine Laboratory
Describing Research Conducted On The Savannah River Site
During The Period September 29, 2000 - September 28, 2005
Under Cooperative Agreement (No. 00-CA-11083600-010)
Between
Virginia Polytechnic Institute \& State University
And
The USDA Forest Service, Savannah River

Submitted To: $\quad$ John Blake, Assistant Manager for Research

USDA Forest Service, Savannah River

P.O. Box 700

New Ellenton, SC 29809

Corresponding Author: Jeffrey R. Walters

Department of Biology

Virginia Polytechnic Institute and State University

Blacksburg, VA 24061-0406

Phone: 540-231-3847

FAX: 540-231-9307

E-MAIL: jrwalt@vt.edu

May 31, 2008 


\section{EXECUTIVE SUMMARY}

This report summarizes results of a five-year study of red-cockaded woodpeckers (Picoides borealis) at the Savannah River Site (SRS) conducted by biologists from Virginia Tech, the Duke Marine Laboratory and the USDA Forest Service at SRS. This project is based on a previous study in which we showed that growth of the red-cockaded woodpecker (RCW) population at SRS likely was limited by poor dispersal success due to an unfavorable spatial distribution of recruitment clusters. The primary objective of the project was to test experimentally the hypothesis that the location of recruitment clusters relative to existing groups was limiting their rate of occupancy. A secondary objective was to evaluate the cost effectiveness of various elements of the SRS management plan for RCWs.

Rates of occupation of two types of recruitment clusters, differing in their spatial relationship to existing woodpecker groups, were compared. Experimental clusters were within $2 \mathrm{~km}$ of three or more existing groups, whereas control clusters had no existing groups within 2 $\mathrm{km}$ of them. Eight recruitment clusters of each type were established in the winter of 2001-2002, and initial response to them was assessed in the RCW breeding season in 2002. Four of eight experimental recruitment clusters $(50 \%)$ were occupied in the 2002 breeding season, whereas only one of eight control recruitment clusters (12\%) was occupied. Those recruitment clusters that were occupied were replaced by new ones, so that ten recruitment clusters of each type were available for occupancy each breeding season, beginning in 2003. The rate of occupation in 2003 was lower than in 2002, but still higher for experimental clusters $(30 \%)$ than for control clusters $(0 \%)$. Rates of occupation fell to near zero after 2003: only one cluster of each type was occupied in 2004 and 2005 combined. At the end of the experiment, seven of the 18 experimental clusters that were constructed were occupied (39\%), compared to two of the 11 control clusters $(18 \%)$. The difference between treatments in occupancy is not statistically significant but the trend in the data supports the idea that placing recruitment clusters near existing groups increases occupancy rate.

We predicted that placing recruitment clusters near existing groups would not only increase their rate of occupation, but also result in high rates of population growth and increased rates of transition from non-breeder to breeder status among juvenile females and helper males (due to their achieving breeding status by occupying such clusters). Our prior work showed these transition rates to be unusually low at SRS compared to other RCW populations. The expectation of enhanced population growth was not realized. The population increased by $11 \%$ (from 37 to 41 groups) in the first year of the study, a rate of growth similar to that during the period analyzed in our previous study ( $12 \%$ annual growth $1995-1998$, from 18 to 25 groups) and the intervening years (14\% annual growth 1998-2001, from 25 to 37 groups). However no additional population growth occurred between 2002 and 2005. The high rates of recruitment cluster occupation in the early portion of the study were reflected in population growth, whereas lack of occupation of recruitment clusters in the latter portion of the study corresponded to a period of no growth.

We attribute the stagnation of population growth and lack of occupation of recruitment clusters in the latter years of the study to low productivity. In our previous study we found that productivity at SRS was exceptionally high, averaging 1.9 fledglings per group during 19951998, compared to long term averages of 1.3-1.5 fledglings per group in other populations. Productivity was considerably lower during the first three years of this study, averaging 1.5 fledglings per group during 2001-2003, but returned to higher levels again in 2004 and 2005. When population growth occurs through the natural processes of budding and pioneering, 
variation in productivity has a large effect on the size of the non-breeding helper and floater classes, but only a small impact on population growth. When recruitment clusters are available, however, many juveniles, floaters and helpers become breeders by occupying these clusters and forming new groups, and this process fuels population growth. Under these conditions population growth tracks productivity, albeit with some delay as many members of a large cohort do not immediately transition from juveniles to breeders but rather spend a year or two as helpers and floaters before dispersing to recruitment clusters to form new groups. We believe this is what occurred during the study, as small cohorts in 2001-2003 resulted in poor growth in 20032005. If this is true, higher productivity in 2004 and 2005 should lead to increased rates of occupation of recruitment clusters and greater population growth in 2006 through 2008 . We suggest such variation in productivity is typical of RCWs and is best viewed as a form of environmental stochasticity related to climatic variation.

Although the improved spatial distribution of recruitment clusters did not result in the population growth anticipated, it did have the predicted impact on transitions to breeding status among juvenile females and helper males. These rates, which previously were unusually low, were as high or higher as those observed in other populations during this study, indicating that ability to disperse to breeding positions was greatly improved. Many helpers and juveniles obtained breeding positions by dispersing to recruitment clusters, but elevated rates of breeder mortality created more breeding vacancies on existing territories as well. Mortality rates were similar to those reported in other populations, suggesting that breeder mortality may have been atypically low during our previous study. We conclude that the combination of more accessible recruitment clusters and more vacancies on existing territories, coupled with reduced competition for breeding vacancies (due to lower productivity) created the improved rates of transition to breeder status observed.

Recruitment clusters are an important element of the management plan for RCWs at SRS and our experiment contributes to evaluating their effectiveness. We further evaluated the potential impact of locating recruitment clusters near existing woodpecker groups using a spatially-explicit, individual-based model of RCW population dynamics. Specifically we simulated the $2001 \mathrm{RCW}$ population, with and without the 16 recruitment clusters employed in the experiment, and compared the results to those of simulations of the 1995 population, with and without the 33 recruitment clusters available in 1995. The simulations involving the 1995 population had been conducted during our previous project. In all cases we simulated population behavior for 20 years, and replicated each simulation 100 times. The mean annual population growth rate among the 100 replicates was much higher for the 2001 population than for the 1995 population, and was improved when recruitment clusters were included. The mean rate for the 2001 population with the 16 recruitment clusters was only slightly less than $1(0.983)$. We conclude that population viability is being improved through both population growth and more strategic placement of recruitment clusters.

We experimentally tested the cost effectiveness of another management element, removal of southern flying squirrels (Glaucomys volans) from RCW cavities. This potentially controversial and labor-intensive technique is intended to improve productivity. To determine the effect of squirrel removal on RCW productivity, we compared reproduction in clusters in which squirrels were removed from cavities when detected during routine monitoring for RCW nesting activity (removal) to reproduction in clusters in which squirrels detected in cavities were allowed to remain (control) over four years, randomly assigning clusters to treatments each year. We found no difference between the two treatments in the proportion of groups that nested or 
nest failure rate, suggesting that this method of squirrel control did not improve availability of cavities for nesting or reduce loss of nests. However, brood size (number of fledglings per successful nest) was higher in clusters in which squirrels were removed in all four years, significantly so in two years, suggesting that squirrels indirectly caused reductions in brood size. Overall productivity (fledglings per group) was higher in treated clusters in only one of four years. We conclude that the practicable method of squirrel control tested is not cost-effective as it produces no benefit in most years and there is no basis, given lack of understanding of the mechanism behind the brood size effect, for predicting in which years it will be beneficial. More intensive methods of squirrel control might produce more benefit in terms of enhanced productivity, but whether the level of effort required could be sustainable in a population as large as that at SRS is questionable.

The SRS RCW population was rescued from extirpation through intensive management that included importing birds from other populations. Once the population reached 30 potential breeding groups in 2000 managers were expected to continue to recover the population without external augmentation. Recruitment cluster construction is the means to that end. The results of our previous project suggested that in the late 1990s population growth may have been limited by the ability of birds seeking breeding positions to locate recruitment clusters. The results of this project indicate that this limitation has been removed by placing recruitment clusters within $2 \mathrm{~km}$ of multiple existing groups. We believe that low productivity limited population growth during the study, but this should be viewed as a temporary, stochastic event. Productivity will continue to be variable, and therefore annual population growth will also be variable, but this variability will not constrain growth over the long term. However, we did note one potential limit on population growth, availability of sufficient suitable habitat to support recruitment clusters and associated new groups of woodpeckers. At SRS in much of the habitat appropriate for RCWs the overstory pines are too young and too dense, groundcover is not sufficiently diverse and hardwood midstory is too extensive. It became progressively more difficult to identify locations with sufficient habitat of sufficient quality to support a new recruitment cluster as the study continued. We believe that shortage of suitable habitat will rapidly become the most important limitation to continued growth of the RCW population at SRS, if it has not already become so.

Only time can increase the age of the pine overstory, but dense overstory, excessive midstory and poor groundcover can be alleviated by thinning the overstory and employing prescribed fire to restore habitat. We recommend an intensive habitat management program designed to restore the conditions that describe high quality RCW habitat over large areas in order to provide sufficient locations for future recruitment clusters. We developed a list of potential locations of future recruitment clusters with associated management prescriptions for restoring habitat to a suitable condition. This can serve as a road map for the intensive habitat management program required to support continued growth of the RCW population at SRS toward the recovery goal of 250 potential breeding groups.

Project funds supported T. Brandon Taylor, a graduate student at Virginia Tech, who received his Master of Science degree in Biology in May 2003. In his thesis research, Mr. Taylor studied the relationship between the arthropod prey of RCWs on the boles of pine trees and the surrounding ground cover vegetation at SRS and two other locations. He was able to confirm that prey are more abundant when the groundcover contains a high percentage of forbs and grasses. Mr. Taylor's thesis constitutes an additional product of this project. 


\section{INTRODUCTION}

This report summarizes results of research on red-cockaded woodpeckers (Picoides borealis) conducted by personnel from Virginia Polytechnic Institute and State University (Virginia Tech), the Duke Marine Laboratory and the USDA Forest Service at the Savannah River Site (SRS), South Carolina, from September 29, 2000 through September 28, 2005. This research was supported by a five-year Cooperative Agreement between Virginia Tech and the USDA Forest Service, Savannah River (No. 00-CA-11083600-010).

\section{RATIONALE AND BACKGROUND}

The red-cockaded woodpecker (RCW) was once a common species in the longleaf pine forest that dominated the Coastal Plain and much of the Piedmont in the Southeast. Its precipitous decline to endangered status can be attributed to habitat loss, especially of longleaf pine (Pinus palustris) ecosystems, and alteration of remaining habitat due to fire exclusion and logging of old growth (Ligon et al. 1986; Jackson 1986; 1994; Walters 1991; Conner et al. 2001; USFWS 2003). The RCW is affected by loss of old growth because it is the only species of woodpecker to excavate cavities exclusively in the trunks of living pines, and thus requires trees old enough to have sufficient heartwood for this purpose. The adverse impact of fire suppression can also be related to cavities. The birds abandon their cavities when the hardwoods that develop in the absence of fire encroach upon them (Jackson 1978; Van Balen and Doerr 1978; Conner and Rudolph 1989; Costa and Escano 1989). This presumably is because the hardwoods provide predators with access to cavities around the resin barrier the birds create on the trunks of their cavity trees (Conner et al. 2001).

RCWs also are unusual in exhibiting a cooperative breeding system (Brown 1987). In such systems some adults, called helpers, assist others in raising young rather than reproducing themselves. In RCWs, most helpers are previous male offspring of the breeding pair (Ligon 1970; Lennartz et al. 1987; Walters et al. 1988; Walters 1990). Helpers become breeders by inheriting a breeding position on their natal territory, or dispersing to fill a vacancy on a neighboring one (Walters et al. 1988; 1992a). Offspring that do not remain as helpers, which include some males and most females, disperse within the first year. Dispersing young may move long distances, although most move only a few territories from their natal site (Walters et al. 1988; 1992a; Daniels and Walters 2000a). Age-specific fecundity and mortality rates, plus a rate of status transition from fledgling to breeder, are sufficient to describe the population dynamics of most avian species. Because of the cooperative breeding system, the population dynamics of RCWs are more complex, and require in addition status transitions from fledgling to helper and helper to breeder (Heppell et al. 1994; Maguire et al. 1995; Letcher et al. 1998).

The population dynamics of the species revolve around the linked features of cooperative breeding and highly valued cavities. Generally, cooperative breeding is thought to evolve under conditions of high variability in territory quality (Stacey and Ligon 1991). Under these conditions, it is advantageous for individuals to remain at home and await a breeding vacancy on a high quality territory in the vicinity, rather than dispersing to wander in search of a vacant territory, which may well be a poor quality one. In the case of the RCW, territories with existing cavities are the high quality ones, those that include all other resources but lack suitable cavities the poor quality ones (Walters 1991). The value of cavities presumably derives from the fact that they typically take many years to excavate, and may be used for decades once completed (Conner and Rudolph 1995; Harding and Walters 2002; 2004). This interpretation of the role of cavities in population dynamics is supported by both empirical and experimental evidence. 
Observed rates of new territory formation are extremely low (Hooper et al. 1991; Walters 1991; Conner et al. 2001; but see Walters 2004), but territories with good cavities remain occupied continuously for decades (Doerr et al. 1989; Harding and Walters 2002). When artificial cavities were added to unoccupied habitat experimentally, the birds moved into the areas in which cavities were placed and formed new groups, but continued to ignore similar control areas to which no cavities were added (Copeyon et al. 1991; Walters et al. 1992b).

Naturally, new territories form by two processes, budding and pioneering (Hooper 1983). Budding involves the splitting of one territory, and its set of cavity trees, into two. Budding is initiated by a helper male from the original territory or an intruding male dispersing from elsewhere (Perkins 2006). The new budded territory contains some previously existing cavities wrested from the original group, but often a new cavity is excavated some distance away from the original trees as well. Pioneering involves the colonization of unoccupied habitat lacking preexisting cavities, and thus always involves the excavation of new cavities. Pioneering invariably is initiated by a dispersing male (Perkins 2006). Due presumably to the time and effort required to excavate new cavities, population growth due to budding is ten times as high as growth due to pioneering in most populations (1-2\% per year versus $0.1-0.3 \%$ per year) (Conner et al. 2001), although there are some exceptions (Walters 2004). Providing cavities in unoccupied habitat (recruitment clusters) can increase population growth through new territory formation 100-fold (i.e., to 10\% per year) (Conner et al. 2001). This is because the process by which recruitment clusters are occupied resembles breeder replacement on existing territories rather than pioneering or budding. Thus either helpers from neighboring groups or dispersing juveniles may occupy a recruitment cluster (Walters et al. 1988; 1992b).

Our current understanding of the population dynamics of RCWs suggests that the best management strategy is one that focuses on territory quality rather than demography. That is, management should focus on preventing abandonment of existing territories and creating additional new territories, rather than on increasing reproduction or reducing mortality (Walters 1991; Conner et al. 2001; Rudolph et al. 2004). Management techniques have been developed with this view of population dynamics in mind. Cavity restrictors (Carter et al. 1989) are designed to reduce territory abandonment by protecting cavities. Construction of artificial cavities (Copeyon 1990; Allen 1991; Copeyon et al. 1991) can be used both to maintain territory quality by providing replacement cavities on occupied territories, and to stimulate population growth through creation of recruitment clusters. Prescribed fire can be used to reduce hardwood midstory, and thereby territory abandonment (Frost et al. 1986; Ware et al. 1993).

Foraging requirements presumably set a limit on the density of high quality territories that can be achieved. RCW territories are very large (Jackson 1994; Conner et al. 2001; USFWS 2003), typically more than 80 ha in longleaf habitat in the Carolinas and Georgia (Hooper et al. 1982; Epting et al. 1995; Walters et al. 2002a).

\section{Red-cockaded Woodpeckers at SRS}

In recent years declines of RCW populations have been reversed, and increases achieved, following the management strategy, and employing the specific techniques, just described (Conner et al. 2001). SRS represents one of the most spectacular examples (Franzreb 1997; Johnston 2005). Managers at SRS rescued the local RCW population from the brink of extirpation, increasing it from one breeding pair in 1985 (Jackson 1990) to over 30 groups in 2000. Management on SRS has included prescribed fire and other methods to control hardwood midstory, construction of recruitment clusters, translocation of individuals from other 
populations to occupy recruitment clusters (DeFazio et al. 1987; Rudolph et al. 1992), control of cavity kleptoparasites (Kappes 1997), and intensely monitoring and aggressively protecting all nests and individuals within the population (Allen et al. 1993; Haig et al. 1993; Franzreb 1997; Edwards et al. 2000; Johnston 2005).

As a population grows larger, it becomes increasingly difficult to provide each individual woodpecker, group and cluster such special attention. The human and fiscal resources required for the level of management intensity that brought the SRS population back from the brink of extinction become increasingly prohibitive, and the cost effectiveness of each management activity becomes increasingly critical. It hence becomes increasingly important that the natural dynamics of the population contribute more to its continuing growth. The challenge that now faces SRS is to identify the most cost-effective ways to positively impact natural population dynamics through management in order to promote continued population growth.

The problem confronting SRS is a general one. Many populations of RCWs currently are of similar, small size, and are well below the population objective set for their management unit (James 1995; USFWS 2003). Devising a means to increase such populations at high rates in a cost-effective manner is a major research and management issue.

\section{The Previous Virginia Tech RCW Project at SRS}

Our research group conducted a two-year project at SRS, from September 1998 to September 2000, prior to this study (Walters et al. 2001). The objective of the previous project was to determine what might limit growth of the RCW population. The project included three components, (1) examining overall population dynamics and important demographic parameters and comparing the SRS data to those from other populations, (2) examining the features of recruitment clusters, and (3) using a spatially-explicit, individual-based model to simulate population growth under various conditions. The results of all three analyses suggested that the spatial distribution of existing groups and the location of recruitment clusters relative to the existing groups were likely to limit population growth at SRS. We will briefly describe these results here; see Walters et al. (2001) for further details.

First, we found that during 1995-1998 productivity of breeders and survival of all age classes were similar to or greater than values observed in other populations, but transitions from non-breeder to breeder status occurred at low rates compared to other populations. Specifically, only $14 \%$ of female fledglings became breeders at age one, compared to $20 \%-30 \%$ in other populations, and only $9 \%$ of male helpers acquired breeding positions each year, compared to $20 \%-25 \%$ in other populations. These results suggested that fledglings and helpers were having difficulty locating breeding vacancies on existing territories and recruitment clusters.

Second, the density of existing groups in the vicinity of recruitment clusters was low at SRS. Chadwick (pers. comm.) found that the density of existing active clusters within $2 \mathrm{~km}$ of a recruitment cluster was one of the most important predictors of whether or not a recruitment cluster would be occupied on Eglin Air Force Base in Florida. Interestingly, Conner and Rudolph (1991) identified this same variable, number of active clusters within $2 \mathrm{~km}$, as an important difference between active and inactive natural clusters in Texas. These results suggest that interactions among neighboring groups are important to population dynamics, recruitment clusters lacking a sufficient number of neighbors may not be detected, and $2 \mathrm{~km}$ is an appropriate distance for defining a neighborhood. The neighbor effect likely is due to the short dispersal range of male helpers: a distance of $2 \mathrm{~km}$ typically corresponds to two or three territories beyond 
the home territory, and three territories is the maximum dispersal distance of helpers (Walters et al. 1988; Daniels 1997).

Population density in the vicinity of recruitment clusters appeared to be impacting their occupancy. Of 11 recruitment clusters constructed prior to 1995 that had $\geq 3$ active clusters within $2 \mathrm{~km}$ of them, six (55\%) were occupied by 2000 . Of 16 that had $<\overline{3}$ active clusters within $2 \mathrm{~km}$ of them, five (31\%) were occupied. Of the 28 recruitment clusters constructed from 1995 through 1998, only one had $\geq 3$ active clusters within $2 \mathrm{~km}$ of it, and 25 had none.

Third, the simulation modeling projected unusually low rates of dispersal between existing groups (including to unoccupied recruitment clusters) in the 1995 population, unusually low rates of occupation of recruitment clusters, and a declining population. Addition of 20 more recruitment clusters at locations already identified by SRS personnel was not projected to improve population behavior. The results of this exercise supported previous modeling that suggested that spatial clumping of territories is critical to population stability generally, and dispersal of non-breeders into breeding vacancies and recruitment clusters specifically (Letcher et al. 1998; Walters et al. 2002b). In the case of SRS, the simulation results suggested that the current spatial distributions of both the current population and the existing and planned recruitment clusters were not ideal.

Significantly, the actual behavior of the SRS population since 1995 has been much more positive than population behavior projected by the model, a tribute no doubt to the impact of intense management. The results of the previous project suggest that it might be possible to both improve population growth rates and reduce management intensity. Specifically, by placing recruitment clusters so as to improve clustering of territories, it might be possible to improve rates of occupancy and thus new group formation, without having to physically move birds so much, or protect nests as aggressively. These possibilities are predicated on the assumption that occupancy of recruitment clusters and transitions from non-breeder to breeder status will be improved by altering placement of recruitment clusters. Rather than base revisions in the SRS RCW management plan on this untested possibility, it is imperative that this important assumption be rigorously examined.

There were too few recruitment clusters with several groups in their vicinity to evaluate the effect of placement on occupancy using existing recruitment clusters. On the other hand, if all new recruitment clusters were put in the vicinity of existing groups, placement of clusters would be only one of several possible explanations of a difference between response to these clusters and response to previous clusters. That is, placement of clusters would be confounded with all other differences between the past and the future, such as population size, annual variation in climate and other changes in management. Therefore the best approach to testing the critical hypothesis that altering the placement of recruitment clusters will improve the dynamics of the SRS RCW population is an experimental one. That assertion was the basis of this project.

\section{OBJECTIVES}

This project had one primary and one secondary objective. The primary objective was to test the hypothesis, through an experiment, that the location of recruitment clusters relative to existing groups determines their rate of occupancy, and thereby the ability of non-breeders to acquire breeding positions and population growth. Specifically, we compared occupancy rates of two types of recruitment clusters, differing in the number of active clusters within $2 \mathrm{~km}$ of them.

The secondary objective was to evaluate elements of the existing management plan for RCWs at SRS (Edwards et al. 2000) with respect to their potential impact on population growth 
rate relative to their cost. Recruitment clusters are one such element, and thus our experiment evaluating spatial distribution of recruitment clusters contributes to the secondary objective, as well as being the primary objective. We also evaluated the potential effectiveness of recruitment clusters in stimulating population growth through model simulations. Finally, we examined a second element of the management plan, nest protection, through a second experiment.

\section{EXPERIMENTAL STUDY OF RECRUITMENT CLUSTER OCCUPANCY Study Design}

The experimental design of the recruitment cluster study involves comparing the rate of occupation of two types of recruitment clusters, differing in their spatial relationship to existing woodpecker groups. Recruitment clusters of the first type, termed experimental clusters, were within $2 \mathrm{~km}$ of $\geq 3$ active clusters when constructed, and $0.5 \mathrm{~km}-1.0 \mathrm{~km}$ from the nearest active cluster. The latter constraint is necessary because habitat closer than $0.5 \mathrm{~km}$ from an existing group might be within the territory of that group (Walters et al. 1988). Control clusters, the second type of recruitment cluster, had no active clusters within $2 \mathrm{~km}$ of them when constructed. To the extent possible, we used previously existing, inactive recruitment clusters in the study. Doing so sometimes required rehabilitating the clusters to make them habitable, especially by replacing cavities that had deteriorated. When the number of existing recruitment clusters that met the spatial criteria was insufficient in a particular year, new recruitment clusters were constructed. New recruitment clusters were placed in appropriate, strategic locations as described in current Forest Service guidelines (USDA 1995). Thus their placement followed current management policy, constrained only by the local density criteria.

At the beginning of the study, our criterion for determining the number of recruitment clusters to provide was that there should be eight available, unoccupied recruitment clusters of each type (i.e., treatment) each year. Clusters were considered occupied if they were active during the breeding season. Clusters that were unoccupied at the end of the breeding season, using August 15 to demarcate that point, were considered available for occupation for the subsequent breeding season. Previously unoccupied clusters that became occupied during the breeding season were replaced through construction of additional, new recruitment clusters during the subsequent winter in order to reach the target level of eight available clusters per treatment. When the population size reached 40 groups in 2002, the criterion was raised to ten available clusters per treatment for the remaining years of the study. We used these criteria to ensure that there would be enough recruitment clusters of each type to support population growth. Elsewhere the maximum rate of population growth observed in the absence of translocation of individuals from other populations has been rate about 10\% (Conner et al. 2001; Walters 2004). We provided an excess of recruitment clusters of each type, roughly twice the minimum number to support $10 \%$ growth, because the locations of individuals likely to occupy recruitment clusters (i.e., helper males, fledgling females) are unpredictable except over short time scales. That is, providing an excess of clusters is necessary to ensure potential for $10 \%$ growth in the face of variation in the spatial distribution of likely occupants. We also distributed the recruitment clusters to match the distribution of the existing population. The existing groups are divided between a northern and a southern subpopulation, separated by more than $10 \mathrm{~km}$ (Figures 1 and 2). Initially we located five control clusters and five experimental clusters in the northern subpopulation (Figure 1) and three control clusters and three experimental clusters in the southern subpopulation (Figure 2). When the criterion was raised to ten available clusters per 
treatment, we located six of each type in the northern subpopulation and four of each type in the southern subpopulation.

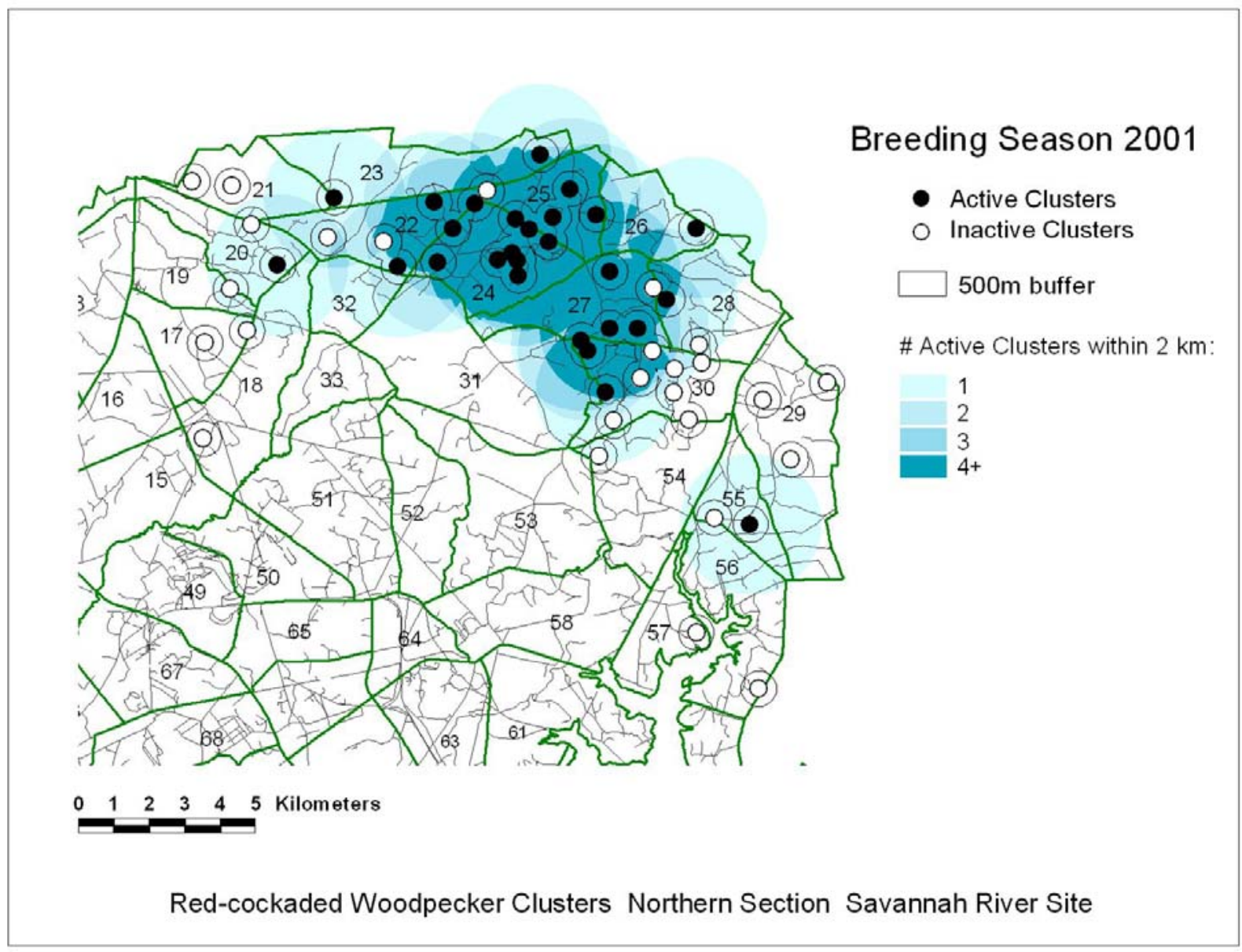

Figure 1. Active and inactive RCW clusters in the northern section of the Savannah River Site in the breeding season of 2001, at the time when recruitment clusters for the experiment were selected. Recruitment clusters were selected based on the number of active clusters within $2 \mathrm{~km}$ of them, which is indicated by the shading. Numbers indicate forest compartments.

Compartments 56 and 57 are part of the southern section but in this and similar figures below are shown with the northern section for convenience. 


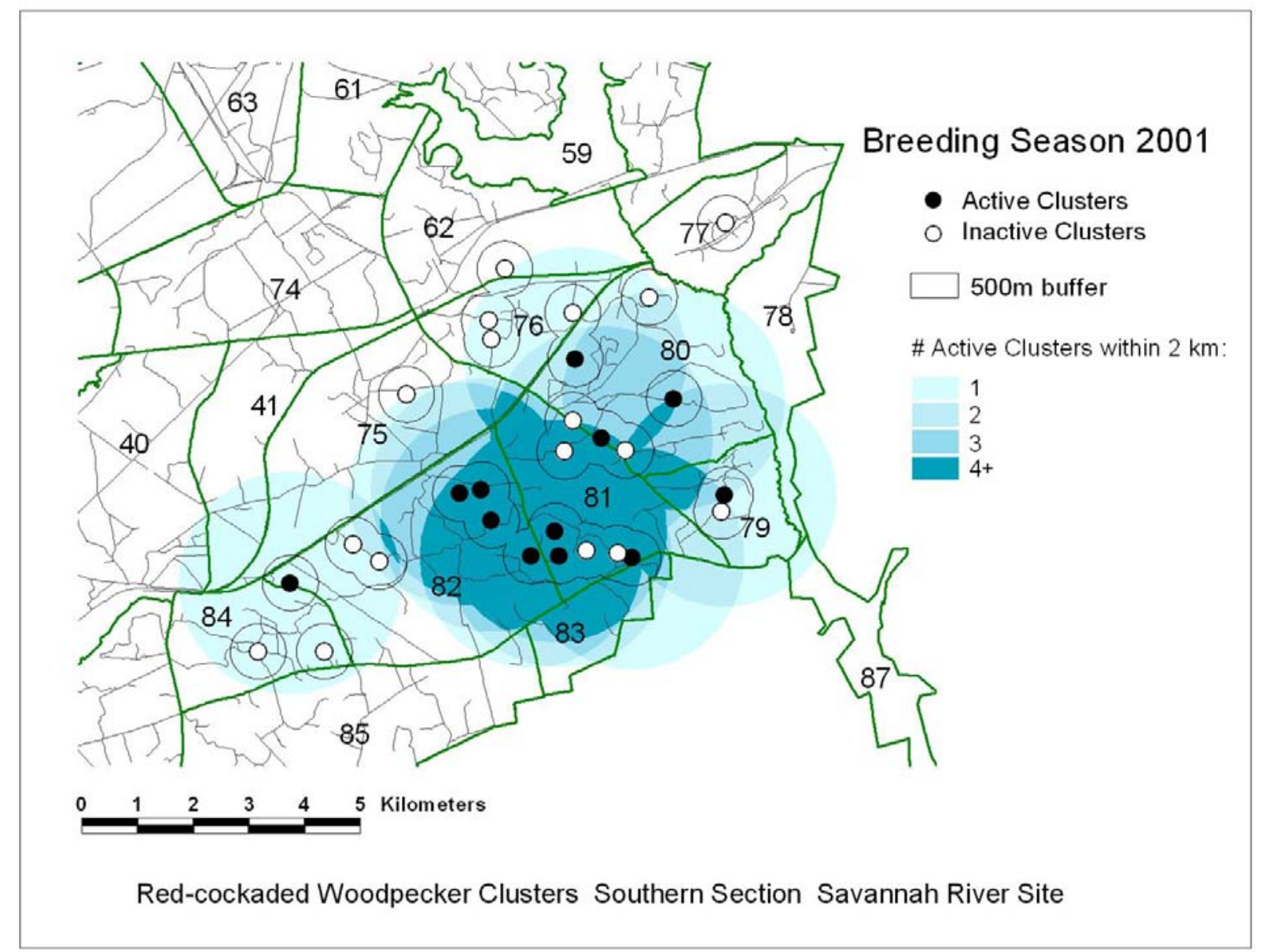

Figure 2. Active and inactive RCW clusters in the southern section of the Savannah River Site in the breeding season of 2001, at the time when recruitment clusters for the experiment were selected. Recruitment clusters were selected based on the number of active clusters within $2 \mathrm{~km}$ of them, which is indicated by the shading. Numbers indicate forest compartments.

We determined, in consultation with SRS managers, the number of recruitment clusters of each type to be constructed each winter and their locations. SRS personnel performed related habitat management and assisted in recruitment cluster construction and collection of demographic data. Each year the activity status (active or inactive) of each cluster was determined, and in each active cluster the resident group of individually identifiable, colorbanded birds was censused and the sex and status (breeder; helper; floater; intruder from another group) of each bird observed was determined. Clusters were assigned to one of the following status categories based on status checks and census results: inactive; occupied by a potential breeding group (pair or pair plus helpers present); occupied by a solitary male (only a single male present); occupied by a single female (only a single female present); and captured (active, but used by one or more members of a group residing in another cluster). Reproduction was monitored in all clusters occupied by a potential breeding group.

\section{Results}

At the outset of the experiment, there were a number of recruitment clusters that qualified as experimental clusters ( $\geq 3$ groups within $2 \mathrm{~km}$ ), and a number that qualified as control clusters 
(no groups within $2 \mathrm{~km}$ ) (Figures 1 and 2). Many existing recruitment clusters did not qualify as either control or experimental clusters because they were within $2 \mathrm{~km}$ of 1-2 active clusters, rather than none or $\geq 3$ (Figures 1 and 2). A few of the recruitment clusters within $2 \mathrm{~km}$ of $\geq 3$ active clusters were too close $(<0.5 \mathrm{~km})$ to one of these clusters to be used in the experiment.

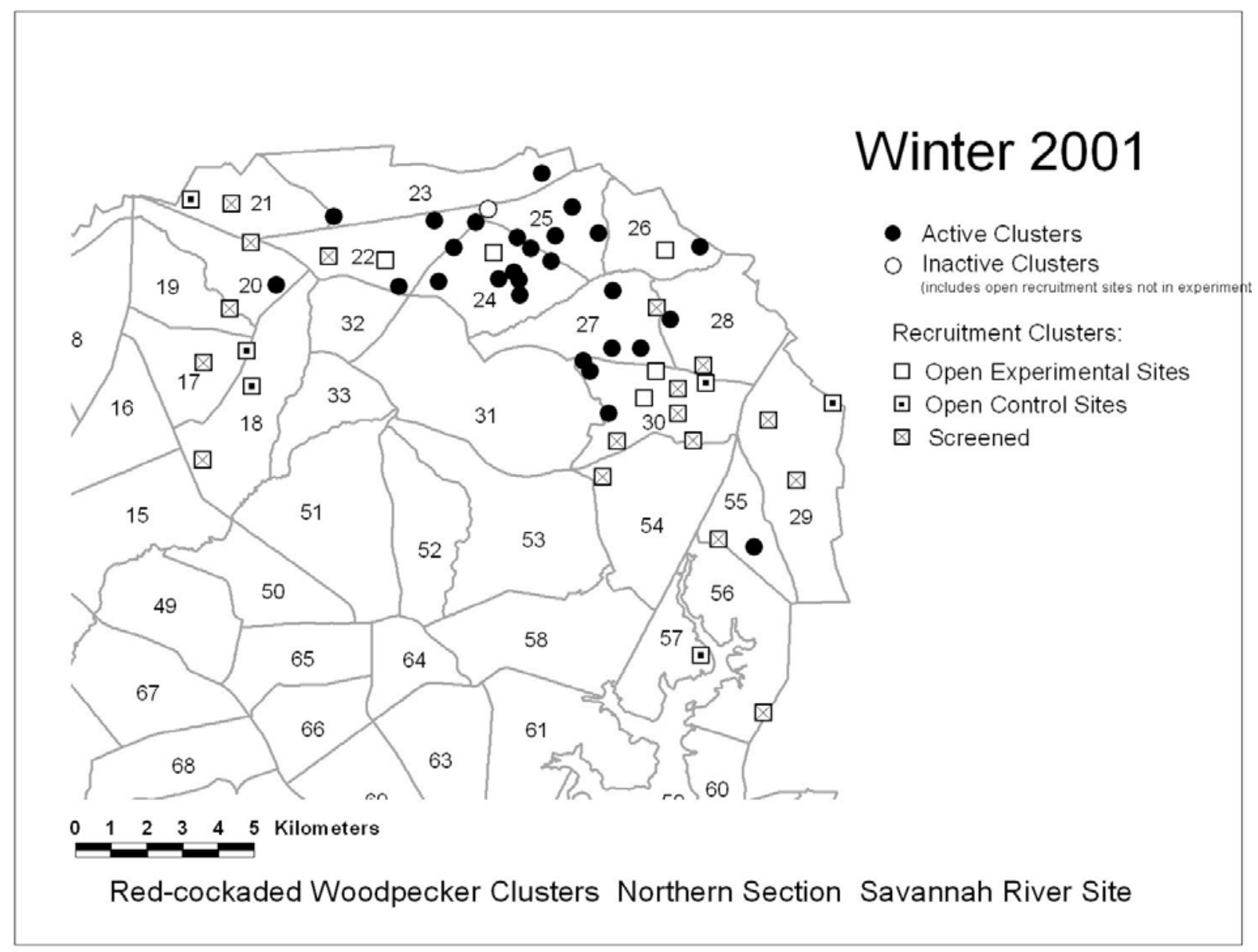

Figure 3. RCW clusters in the northern section of SRS at the outset of the experiment in the winter of 2001-2002, including active clusters, experimental recruitment clusters, control recruitment clusters and recruitment clusters in which all cavities were screened. The inactive cluster is a recruitment cluster that was too close to an active cluster to be included in the experiment. Numbers indicate forest compartments.

To begin the experiment we used seven of these existing recruitment clusters as control clusters, and six as experimental clusters (Figures 3 and 4). One new control cluster and two new experimental clusters were constructed during the winter of 2001-2002, all in the northern subpopulation, to reach the desired number of available clusters (Figure 3). Seven other existing recruitment clusters qualified as control clusters but were not needed for the initial set. The cavities in these clusters were screened so that the birds could not use them. Cavities in the 19 existing recruitment clusters that did not qualify as either control or experimental clusters because they were within $2 \mathrm{~km}$ of 1-2 active clusters also were screened (Figures 3 and 4). Cavities in the recruitment clusters that were too close $(<0.5 \mathrm{~km})$ to an existing active cluster to be viable as independent sites were left open, and these sites were counted as inactive clusters 
(Figures 3 and 4). We considered these cavities to belong to the nearby group. One existing recruitment cluster was excluded from the experiment because it became active in the fall of 2001.

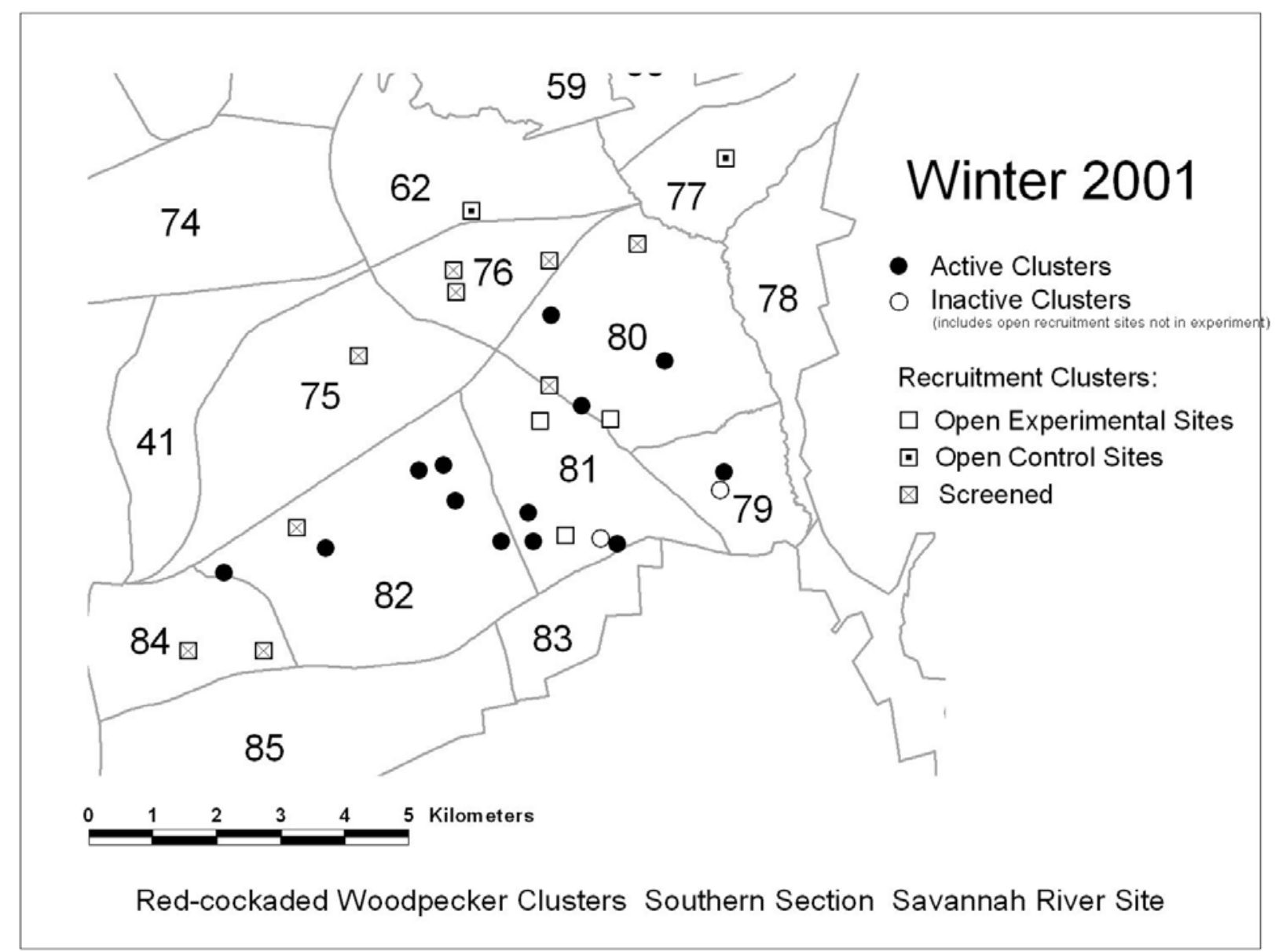

Figure 4. RCW clusters in the southern section of SRS at the outset of the experiment in the winter of 2001-2002, including active clusters, experimental recruitment clusters, control recruitment clusters and recruitment clusters in which all cavities were screened. The inactive clusters are recruitment clusters that were too close to an active cluster to be included in the experiment. Numbers indicate forest compartments.

We reported on occupancy of the first set of recruitment clusters in the 2002 breeding season in the Interim Project Report (Walters et al. 2003) previously submitted to SRS. In that first year, four of eight experimental clusters $(50 \%)$ and one of eight control clusters $(12 \%)$ were occupied. After this promising initial response, recruitment cluster occupation declined dramatically (Figure 5). The rate of occupation in 2003 was lower than in 2002, but still higher for experimental clusters $(30 \%)$ than for control clusters $(0 \%)$. Rates of occupation fell to near zero after 2003: only one cluster of each type was occupied in 2004 and 2005 combined (Figure 5). At the end of the experiment, seven of the 18 experimental clusters that were constructed were occupied (39\%), compared to two of the 11 control clusters $(18 \%)$. The difference between treatments in occupancy is not statistically significant $\left(\mathrm{X}^{2}{ }_{1}=1.35, p>0.2\right)$. 


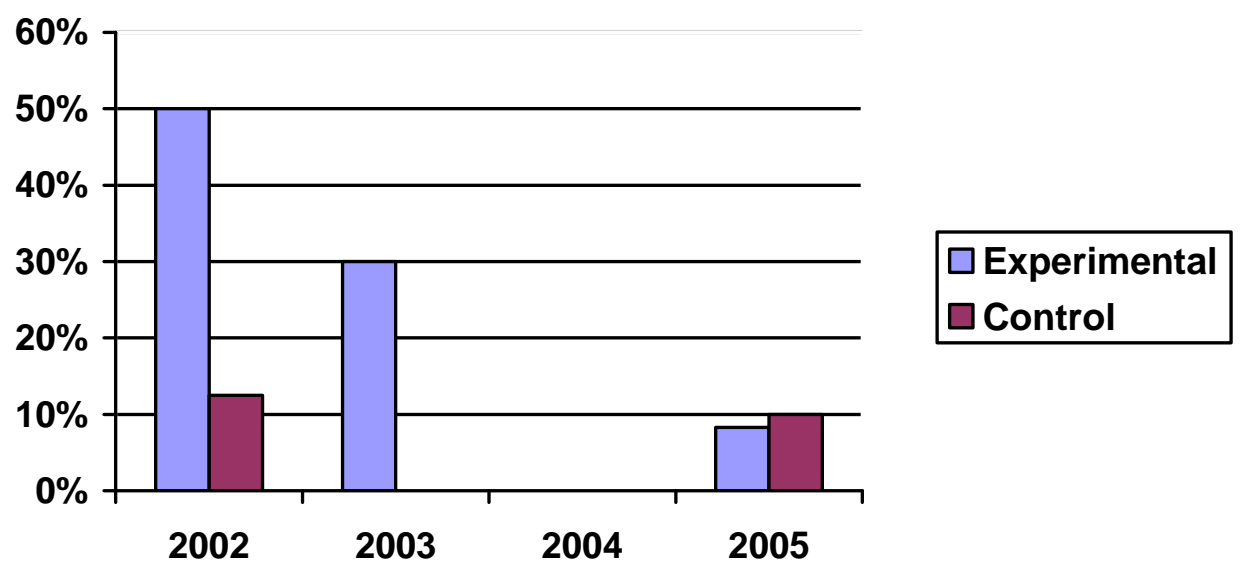

Figure 5. Proportion of available recruitment clusters occupied each year, by treatment. $\mathrm{N}=$ eight clusters of each type in 2002, and ten clusters of each type in 2003-2005, except that $n=12$ for experimental clusters in 2005 due to classification of recruitment clusters that were occupied and subsequently abandoned as available.

With only one exception, occupation of recruitment clusters occurred in the first or second year they were available (Figure 6). Data from other populations suggest that occupancy of recruitment clusters peaks in the second year of availability, remains fairly high in the third year, and declines thereafter (Walters et al. 2004). We suspect that the different pattern observed during this experiment is a byproduct of the factors that caused population growth to cease during 2003-2005 (see below) rather than evidence of an atypically rapid decline in the attractiveness of recruitment clusters.

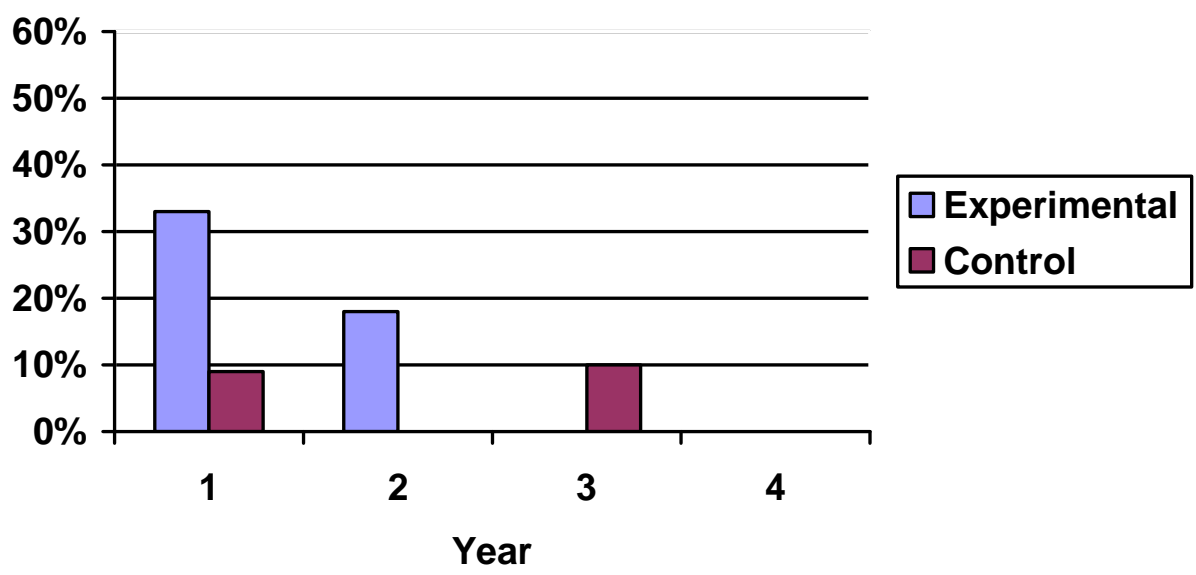

Figure 6. Probability of occupancy of available recruitment clusters as a function of years since construction, by treatment. Year $1=$ the first breeding season following construction. Sample sizes are 18,11, 7 and 4 for experimental clusters, and 11, 10, 10 and 7 for control clusters.

Because the rate of occupancy of recruitment clusters declined over the course of the study, the number of new recruitment clusters constructed each winter also declined. Only 13 more recruitment clusters were added to the original 16 , and nine of those were constructed in 
the winter of 2002-2003 following the high occupancy rates in the breeding season of 2002 (Figure 5) and the increase in the availability criteria that year from eight to ten available clusters per treatment. Only three new recruitment clusters were constructed in the winter of 2003-2004, and only one in the winter of 2004-2005. Of these 13 additional recruitment clusters, only one was a previously existing recruitment clusters that was unscreened; the remaining 12 were new sites. The previously existing cluster that was used did not qualify for inclusion in the experiment originally because it was within $2 \mathrm{~km}$ of two active clusters, but population growth resulted in a third active cluster within $2 \mathrm{~km}$, so that it qualified as an experimental cluster.

\section{Conclusions}

Despite a promising response in the first year, over the course of the study the rate of occupation of recruitment clusters was not elevated by their improved spatial distribution relative to existing groups as anticipated. However most of the recruitment clusters that did get occupied were experimental clusters, suggesting that clusters placed in the vicinity of several existing groups are more likely to get occupied. We conclude that other aspects of population dynamics rather than location of recruitment clusters were responsible for low occupancy rates during the study (see below) and recommend that SRS continue to follow the criterion used for the experimental clusters in locating recruitment clusters in the future. The best available evidence, although not definitive, supports the idea that recruitment clusters placed within dispersal range of several existing groups are most likely to be occupied. Furthermore, when such recruitment clusters do get occupied the spatial clustering of the population is increased, and clustering is known to improve population dynamics and thereby population viability (Walters et al. 2002a). Thus this strategy improves the spatial distribution of the population while increasing its size.

\section{ANALYSIS OF DEMOGRAPHY}

We predicted that placing recruitment clusters near existing groups would not only increase their rate of occupation, but also would enhance population growth. The anticipated enhancement of population growth rate did not occur. The population increased by $11 \%$ (from 37 to 41 groups) in the first year of the study, a rate of growth similar to that during the period analyzed in our previous study (12\% annual growth during 1995-1998, from 18 to 25 groups) and the intervening years (14\% annual growth during 1998-2001, from 25 to 37 groups) (Figure 7). However no additional population growth occurred between 2002 and 2005. The number of active clusters increased during the first two years of the study but not thereafter (Figure 7). There were 39 active clusters at the outset of the study (2001 breeding season, Figures 1 and 2) and 45 at the end of the study (2005 breeding season, Figures 8 and 9).

Although historically most active clusters at SRS have been occupied by potential breeding groups, this was not the case during the period when occupation of recruitment clusters was low (2003-2005) (Figure 7). This is symptomatic of an unfavorable period of population dynamics. Note however that the increase in number of active clusters observed during the study period (2001-2005) was matched by a corresponding increase in the number of potential breeding groups in the year following the study (2006), suggesting a return to more favorable population dynamics. Many of the active clusters that did not contain breeding groups during 2003-2005 were in fact recruitment clusters (7 of 17). Recruitment clusters are often occupied by solitary individuals or captured initially, but then progress to occupation by breeding groups (Walters et al. 1995; 2004a). That was indeed the case in this study. 


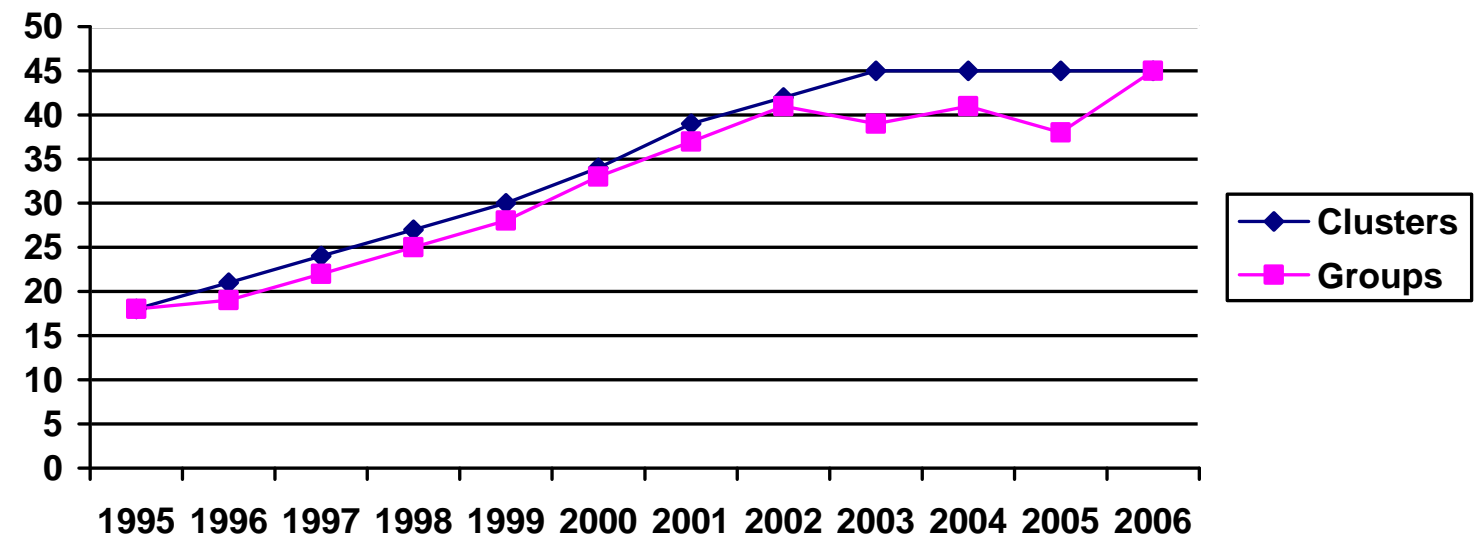

Figure 7. Number of active clusters (clusters) and potential breeding groups (groups) of RCWs at SRS from 1995 to 2006.

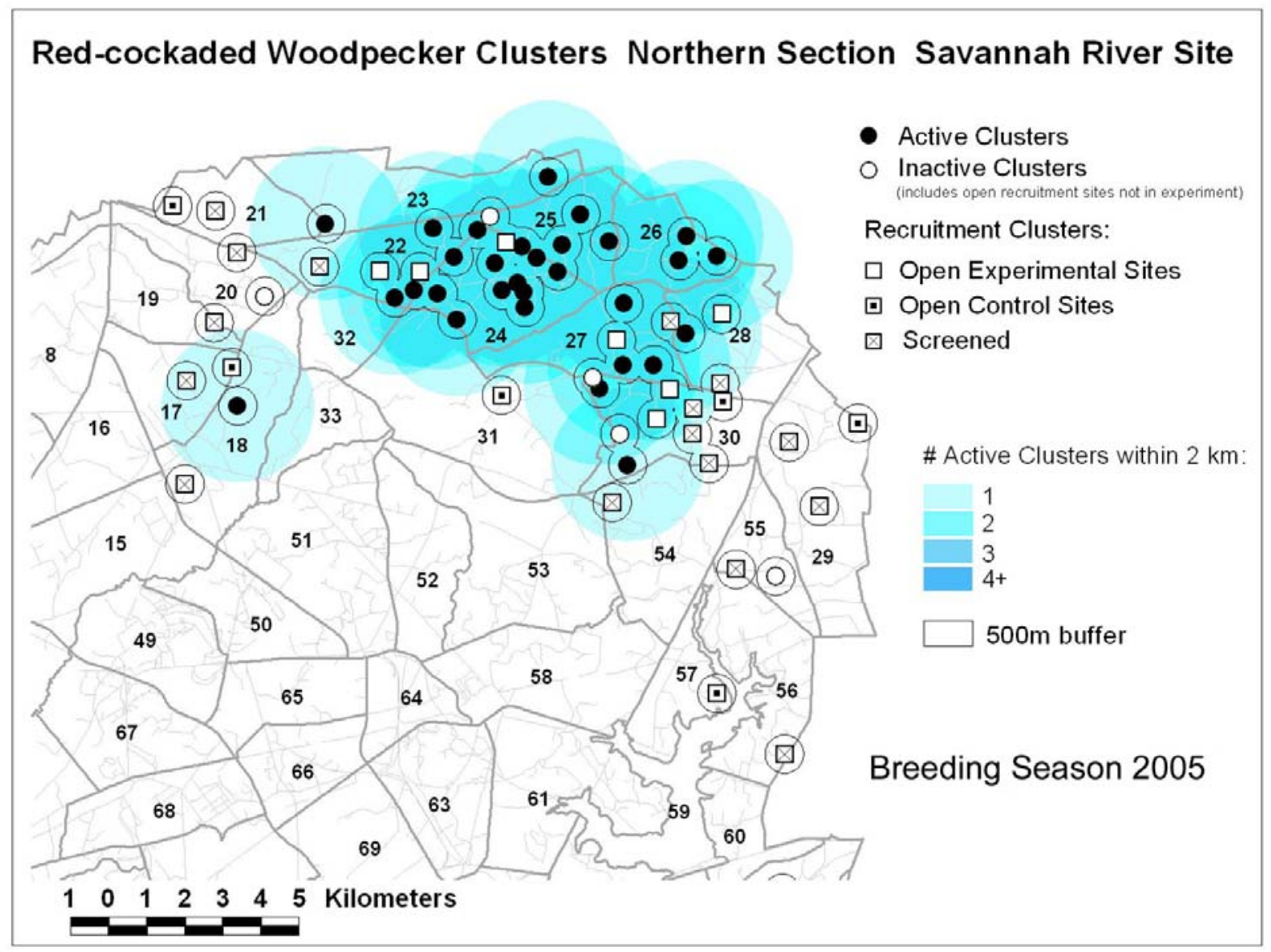

Figure 8. RCW clusters in the northern section of SRS in the breeding season of 2005, including active clusters, experimental recruitment clusters not yet occupied, control recruitment clusters not yet occupied, recruitment clusters in which all cavities were screened and inactive clusters that are not part of the experiment. Numbers indicate forest compartments. 


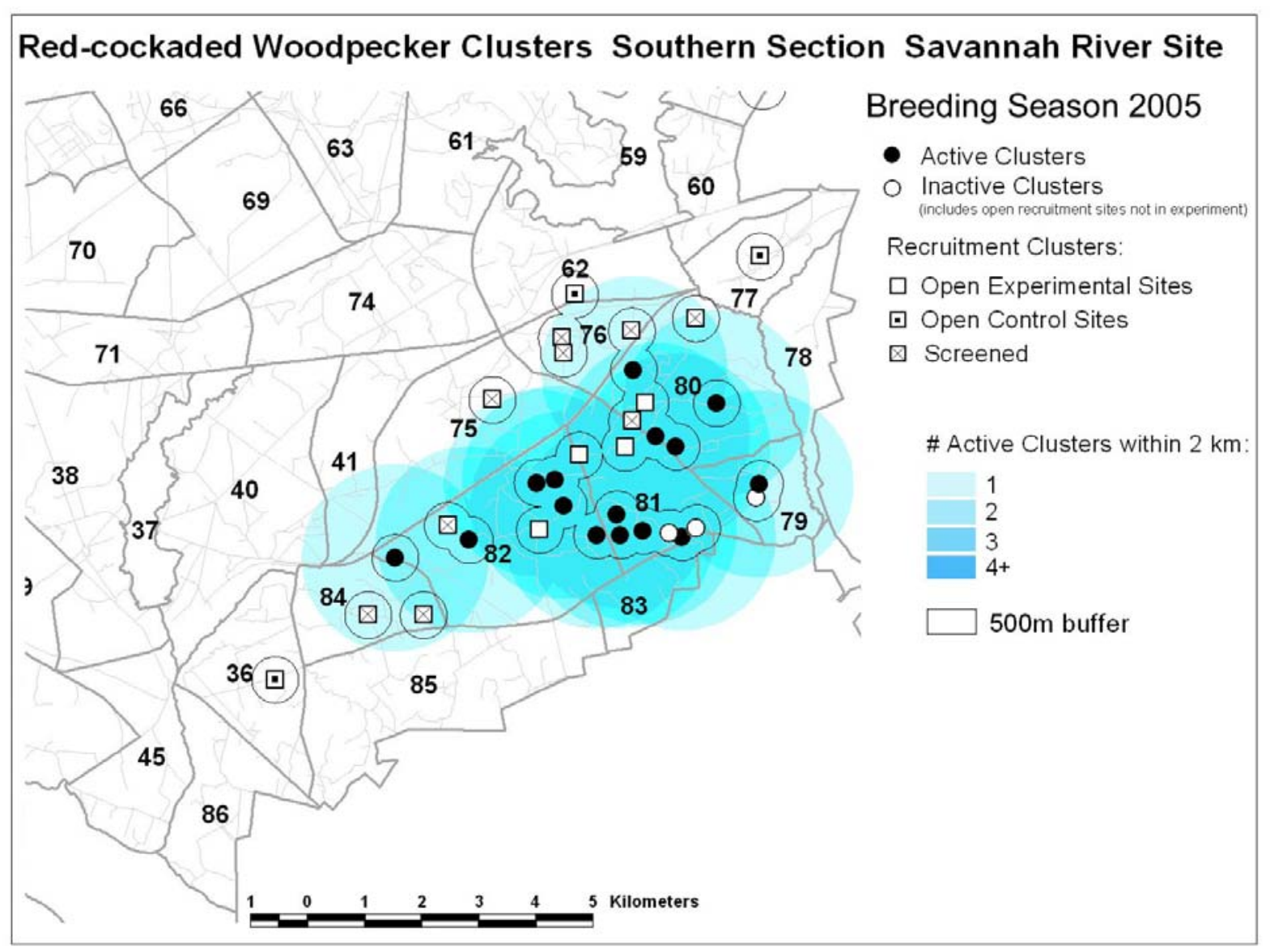

Figure 9. RCW clusters in the southern section of SRS in the breeding season of 2005, including active clusters, experimental recruitment clusters not yet occupied, control recruitment clusters not yet occupied, recruitment clusters in which all cavities were screened and inactive clusters that are not part of the experiment. Numbers indicate forest compartments.

At the completion of the study there were still 25 previously existing recruitment clusters that remained screened because they were not needed, or did not qualify for the experiment, and there were ten available experimental clusters and nine available control clusters (Figures 8 and 9). Occupation of recruitment clusters accounted for the addition of nine active clusters, and at the end of the study six of these nine clusters were occupied by nesting groups. Growth through recruitment cluster occupation was somewhat offset by abandonment of four previously existing clusters that had been active at the outset of the study. Occupation of one previously existing cluster that was inactive at the beginning of the study accounted for the remaining active cluster added to the population during the study.

Although population growth and rates of occupation of recruitment clusters were not elevated in response to improved spatial distribution of recruitment clusters, the predicted increase in transition rates of fledgling females and helper males to breeding status did occur. These rates increased substantially compared to our previous study, to rates similar to those observed in other populations, nearly doubling in the case of juvenile females and nearly tripling in the case of helper males (Table 1). That transitions to breeding status were most improved for helper males (Table 1) is consistent with an effect of improved spatial distribution of recruitment 
clusters because dispersal of this class of individuals is most limited in distance. More occupation of recruitment clusters by helper males in turn likely increases the frequency with which fledgling females acquire breeding positions in recruitment clusters because helper male occupation creates a breeding position that a female can occupy. In contrast, male fledglings disperse longer distances and therefore are less impacted by the spatial distribution of recruitment clusters. Indeed the improved distribution of recruitment clusters during the study period did not result in an increased rate of transition to breeding status of fledgling males, although this rate remained high relative to other areas (Table 1). We believe this rate is high at SRS because there are many recruitment clusters available relative to population size, and occupation of recruitment clusters is a primary means by which young males, who do not compete well for vacancies on existing territories, acquire breeding positions.

Table 1. Annual status transition probabilities from four RCW populations, including Savannah River (SRS) prior to (1995-1998) and during (2001-2005) our study, North Carolina Sandhills, and Camp Lejeune Marine Base and Croatan National Forest in coastal North Carolina.

Transition probabilities are the percentage of individuals in the fist status class in year 1 that are alive and in the second status class in year 2. Solitary males are included in the Breeder Male category in this analysis. Data from populations other than SRS are the same as in our prior study (Walters et al. 2001) rather than updated data.

\begin{tabular}{|c|c|c|c|c|c|}
\hline & SRS 95-98 & SRS 01-05 & Sandhills & Lejeune & Croatan \\
\hline Females & & & & & \\
\hline Fledgling to Helper & $9 \%$ & $6 \%$ & $1 \%$ & $8 \%$ & $3 \%$ \\
\hline Fledgling to Breeder & $14 \%$ & $26 \%$ & $29 \%$ & $18 \%$ & $23 \%$ \\
\hline Males & & & & & \\
\hline Fledgling to Helper & $37 \%$ & $32 \%$ & $27 \%$ & $43 \%$ & $28 \%$ \\
\hline Fledgling to Breeder & $14 \%$ & $15 \%$ & $9 \%$ & $4 \%$ & $6 \%$ \\
\hline Helper to Breeder & $9 \%$ & $24 \%$ & $27 \%$ & $19 \%$ & $19 \%$ \\
\hline
\end{tabular}

That increases in rates of transition from non-breeder to breeder status among helper males and juvenile females were driven, at least in part, by improved occupancy of recruitment clusters is supported by the fact that these transition rates were highest between 2001 and 2002 (Figure 10), when rates of occupation of recruitment clusters also were highest (Figure 5). Many of the transitions during this year involved occupation of recruitment clusters by non-breeding birds. However, note that transition rates were lowest between 2002 and 2003 (Figure 10) when recruitment cluster occupation rates were still fairly high (Figure 5), and were reasonably high in the following two years (Figure 10) despite very low rates of recruitment cluster occupation (Figure 5). New recruitment clusters represent one source of breeding vacancies for nonbreeding birds. Mortality of breeders is the other source, and it appears that increases in nonbreeder to breeder transition rates was driven in part by increased mortality of breeders during the study compared to prior years (Table 2). Elevated levels of breeding female mortality (Table 2) likely contributed to increased ability of female fledglings to acquire breeding positions, but interestingly, among years breeding transitions of fledgling females tracked mortality of breeding males rather than mortality of breeding females (Figure 10). Transition rates of helper and fledgling males tracked mortality of breeding males as well (Figure 10). In all cases, transition rates were higher when breeding male mortality was higher. Mortalities of breeding males of course create breeding vacancies that fledgling or helper males may fill, but in addition when a 
breeding male dies his mate often disperses to another group, creating a female breeding vacancy as well. In some instances breeding females disperse because their son inherits breeding status on the territory, and in other cases females disperse to avoid pairing with young males (Daniels and Walters 2000b). We believe that creation of female breeding vacancies due to deaths of breeding males explains why transition rates of female fledglings tracked mortality of breeding males.

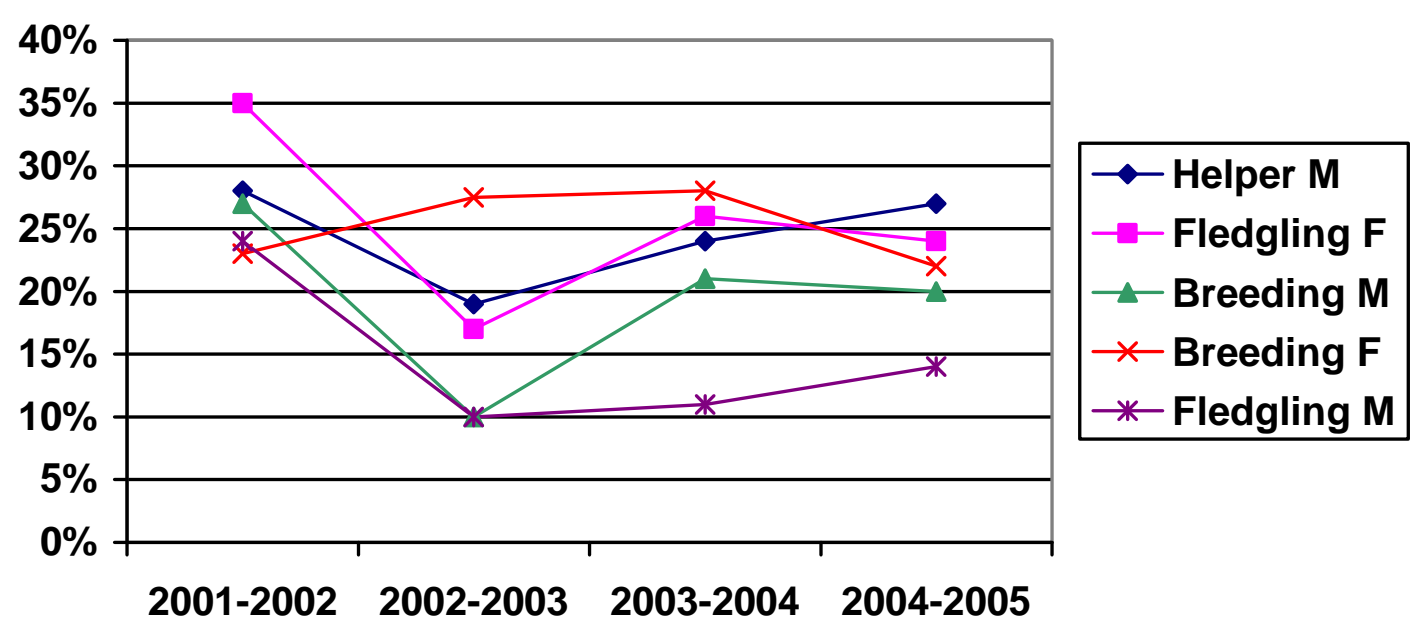

Figure 10. Annual mortality of breeding males and breeding females plotted against rates of transition to breeding status for helper males, fledgling females and fledglings males during the four years of the study. Transition probabilities are the percentage of individuals in the first status class in year 1 that are alive and in the second status class in year 2.

Table 2. Annual mortality rates of various status classes of RCWs at Savannah River (SRS) prior to (1995-1998) and during (2001-2005) this study, and in three other populations (North Carolina Sandhills; Camp Lejeune Marine Base and Croatan National Forest in coastal North Carolina). Mortality is calculated as the proportion of individuals alive in one breeding season that are not resighted the next breeding season. Data from populations other than SRS are the same as in our prior study (Walters et al. 2001) rather than updated data.

\begin{tabular}{|c|c|c|c|c|c|}
\hline & SRS 95-98 & SRS 01-05 & Sandhills & Lejeune & Croatan \\
\hline Fledgling male & $43 \%$ & $50 \%$ & $50 \%$ & $41 \%$ & $54 \%$ \\
\hline Fledgling female & $66 \%$ & $64 \%$ & $58 \%$ & $57 \%$ & $64 \%$ \\
\hline Breeding female & $17 \%$ & $25 \%$ & $29 \%$ & $23 \%$ & $25 \%$ \\
\hline Breeding male & $8 \%$ & $19 \%$ & $24 \%$ & $18 \%$ & $20 \%$ \\
\hline Helper male & $20 \%$ & $24 \%$ & $17 \%$ & $22 \%$ & $22 \%$ \\
\hline
\end{tabular}

Comparison to other populations indicates that mortality rates of breeders during the study were not abnormally high, but rather that they were unusually low during the previous period (i.e., 1995-1998) (Table 2). Certainly the observed mortality rates cannot explain the lack of population growth during the study. Because of the presence of non-breeding helpers (and floaters), in RCWs fluctuations in breeder mortality normally are not reflected in changes in population size as measured by number of potential breeding groups, but rather by fluctuations in the number of non-breeders (Walters 1991). That is, helpers and floaters (as well as juveniles) 
replace deceased breeders, buffering the impact of breeder mortality on the number of breeding groups. When population growth is limited to the natural processes of budding and pioneering, non-breeders buffer impacts of variation in productivity on population size as well. That is, high productivity is reflected in increases in the non-breeding class and low productivity in decreases in this class, but the number of groups remains relatively stable. Under these conditions the vast majority of helpers and floaters who become breeders do so by replacing deceased breeders rather than by forming new groups, as budding and pioneering are difficult to achieve and therefore are rare events. When recruitment clusters are available, however, many floaters and helpers (as well as juveniles) become breeders by occupying these clusters and forming new groups, and this process fuels population growth. Thus when recruitment clusters are being used to stimulate population growth, productivity, unlike breeder mortality, can impact growth rates. Typically there is a time lag in this effect as many members of a large cohort do not immediately transition from juveniles to breeders but instead spend a year or two as helpers and floaters before dispersing to form new breeding groups (Walters 1990). Indeed such an effect of productivity was evident in the simulations we ran in our previous study in a projected $10 \%$ increase in annual population growth rate when productivity was increased by 0.7 fledglings per group (Walters et al. 2001).

We believe that a period of poor productivity contributed, at least in part, to low rates of population growth and recruitment cluster occupation during the study. In our previous study we reported that productivity at Savanna River was exceptionally high during 1995-1998, averaging 1.9 fledglings per group, compared to long term averages of 1.3-1.5 fledglings per group in other populations (Walters et al. 2001). Productivity was considerably lower during the first three years of this study, averaging 1.5 fledglings per group during 2001-2003, but returned to higher levels again in 2004 and 2005 (Table 3). Thus the one and two-year-old helpers and floaters that often occupy recruitment clusters (Perkins 2006) were relatively scarce in 2004 and 2005 when rates of recruitment cluster occupancy were low (Figure 5) and population growth stagnated (Figure 7). If fluctuations in productivity impact population growth, growth rates should be elevated in 2006 through 2008 due to the higher levels of productivity in 2004 and 2005 . The sharp increase in number of potential breeding groups between 2005 and 2006 (Figure 7) supports this notion.

Table 3. Productivity of RCWs from various populations. Values for a span of years are means among years, and ranges among those years are given in parentheses.

\begin{tabular}{|c|c|}
\hline Population & Productivity (Fledglings/Group) \\
\hline North Carolina Sandhills, 1980-1998 & $1.4(1.2-1.7)$ \\
\hline Camp Lejeune Marine Base, NC, 1986-1998 & $1.5(1.0-2.0)$ \\
\hline Croatan National Forest, NC, 1989-1997 & $1.4(1.1-1.6)$ \\
\hline Eglin Air Force Base, FL, 1992-1998 & $1.3(1.2-1.6)$ \\
\hline Savannah River 1995-1998 & $1.9(1.6-2.3)$ \\
\hline Savannah River 2001 & 1.46 \\
\hline Savannah River 2002 & 1.46 \\
\hline Savannah River 2003 & 1.51 \\
\hline Savannah River 2004 & 1.85 \\
\hline Savannah River 2005 & 1.79 \\
\hline
\end{tabular}


RCWs exhibit considerable annual variation in productivity (Walters 1990) and the low values observed during 2001-2003 are well within the range reported for other populations (Table 3). The cause of this variation is not well understood but it appears to be linked to climatic variation and in this case was likely related to the drought that gripped the region through 2001. We do not believe this is something with which managers should be concerned but rather a manifestation of environmental stochasticity characteristic of the ecosystem.

Productivity can be increased through improvement of foraging habitat quality (USFWS 2003) and we expect such increases to occur in response to ongoing habitat management at SRS, but this will not dampen annual variation. Hence managers at SRS should expect to continue to see annual variation in productivity, and corresponding variation in annual population growth. We do not believe that lower productivity during 2001-2003 reflects any deterioration in habitat condition as productivity returned to high levels in 2004 and 2005.

\section{Conclusions}

We conclude that conditions were much more conducive to acquisition of breeding status by juvenile females and helper males during this study than during the previous one. We believe this was due in part to the improved spatial distribution of recruitment clusters (i.e., placement of recruitment clusters near existing groups) and in part to more favorable demographic conditions (i.e., higher breeder mortality producing more breeding vacancies coupled with lower productivity that reduced competition among non-breeders for those vacancies). We attribute the stagnation of population growth in the latter years of the study in part to low productivity, and predict that higher productivity in 2004 and 2005 will lead to increased rates of occupation of recruitment clusters and increased population growth in 2006 through 2008. We conclude that the combined results of the recruitment cluster experiment and our analysis of demography indicate that placing recruitment clusters within $2 \mathrm{~km}$ of several existing RCW groups will be a successful strategy for stimulating population growth.

We also conclude that fluctuations in productivity have impacted population growth in the years since importing birds from other populations ceased. We suggest that significant population growth through 2002 was fueled by high levels of productivity in the late 1990s, and that the absence of further growth in 2003-2005 reflects low productivity during 2001-2003. We consider below an additional factor that likely limited population growth in the latter years of the study, lack of suitable habitat in which to place recruitment clusters.

\section{EVALUATION OF THE RCW MANAGEMENT PLAN}

The SRS RCW management plan (Edwards et al. 2000) contains all the elements required of a management strategy that will promote population growth (Walters 1991; Conner et al. 2001; Rudolph et al. 2004). It describes for example how the landscape will be managed to provide foraging habitat, how hardwood midstory will be controlled, and how tools such as recruitment stands and artificial cavities will be used. In essence, it is a broad outline of how the RCW population will be managed. The results of this study can be used to fill in important details about how the plan will be implemented on the landscape. Details of implementation have the potential to determine whether or not a sound management plan is successful, and whether resources are used in a cost-effective manner.

Besides the recruitment cluster experiment described above, we conducted two activities related to management plan evaluation as part of this project. First, we employed the same model of RCW population dynamics used in the previous project to evaluate the impact on 
population growth of the new strategy for determining spatial locations of recruitment clusters. Second, we conducted an experiment to test the impact of removing southern flying squirrels (Glaucomys volans) from RCW cavities on productivity of the woodpeckers.

\section{Testing the Effect of Recruitment Cluster Placement Using Model Simulations}

The first activity supplements the recruitment cluster experiment as an additional evaluation of the impact of employing a new strategy for locating recruitment clusters. This modeling exercise was completed in 2002 and was described in detail in the Interim Project Report previously submitted to SRS. We will briefly summarize our findings here. Refer to the Interim Project Report for further details.

In our previous project we simulated the behavior of the $1995 \mathrm{RCW}$ population at SRS, and included the impact of existing and planned recruitment clusters in the analysis (Walters et al. 2001). In the current modeling exercise, we simulated the behavior of the $2001 \mathrm{RCW}$ population, and included the 16 recruitment clusters used in the experiment (but no other recruitment clusters) in the simulation. Comparing the results of the previous simulation with those from the new one serves as an assessment of the degree to which the viability of the population improved between 1995 and 2001, as a result of both increased population size and an altered strategy for placing recruitment clusters. In the 2001 analysis there are many fewer recruitment clusters than in the 1995 analysis (16 compared to 53), but some are placed close to multiple existing active clusters.

The model employed in the simulations is a spatially-explicit, individual-based model rather than a simple matrix model such as those typically used to project population dynamics (Beissinger and Westphal 1998). Matrix models cannot accurately simulate population dynamics of RCWs, because they cannot incorporate spatial constraints on helper dispersal, whereas our model captures the effect of spatial distribution of territories on dispersal. The model is described in detail in Letcher et al. (1998) and Walters et al. (2002b).

We simulated the population for a 20 -year period, and replicated each simulation scenario 100 times. For each replicate, each of the 39 territories active in 2001 had a $90 \%$ probability of being occupied by a breeding pair, and territories without a breeding pair contained a solitary male. A number of helpers equal to one-half the number of territories was added randomly to the territories with pairs, so that about one-half of the territories had no helpers, and a few had more than one. The ages of the birds were assigned randomly. Recruitment clusters were placed on the landscape as open territories that could be occupied by dispersing birds. Demographic and environmental stochasticity were simulated as described in Walters et al. (2002b).

The mean annual population growth rates were less than 1.0, indicating a declining population, for all four scenarios simulated, the 1995 population, the 1995 population with recruitment clusters, the 2001 population and the 2001 population with recruitment clusters (Table 4). However the growth rate of the 2001 population was substantially greater than that of the 1995 population. Furthermore, despite their small number, recruitment clusters were projected to improve the population growth rate in the simulations of the 2001 population. 
Table 4. Mean annual population growth rate among 100 replicate simulations, for four simulation scenarios. The number of available territories on the landscape, including recruitment clusters, is indicated for each scenario.

\begin{tabular}{|c|c|c|}
\hline Simulation Scenario & Mean Annual Growth Rate & Number of Territories \\
\hline 1995 Population & 0.918 & 17 \\
\hline 1995 Population + Recruitment Clusters & 0.945 & 50 \\
\hline 2001 Population & 0.974 & 39 \\
\hline 2001 Population + Recruitment Clusters & 0.983 & 55 \\
\hline
\end{tabular}

\section{Flying Squirrel Control Experiment}

A number of species of birds, mammals, reptiles, amphibians and insects use cavities excavated by RCWs (Conner et al. 2001; USFWS 2003). Many of these species only use cavities that have been abandoned by the RCWs and thus benefit from the presence of RCWs, but do not impact them in any way. A few species, notably the pileated woodpecker (Dryocopus pileatus), enlarge the cavities to the point that they are no longer acceptable to RCWs. It is critical that excessive loss of cavities to pileated woodpeckers be prevented by protecting cavities with cavity restrictors (Carter et al. 1989), because loss of cavities can render territories unsuitable, and thus impact population growth (Walters 1991; Conner et al. 2001). Indeed, the SRS management plan provides for such protection of cavities (Edwards et al. 2000).

The appropriate management responses to species that use only abandoned cavities (ignore them) and to species that greatly enlarge cavities (protect cavities with restrictors) are clear. More problematic are cavity kleptoparasites (Kappes 1997), that is, species that usurp active cavities from RCWs but enlarge them little or not at all. These species, for example southern flying squirrels, red-bellied woodpeckers (Melanerpes carolinus) and red-headed woodpeckers (M. erythrocephalus), do not destroy cavities, and RCWs may reclaim them once the kleptoparasite is gone. However, cavity kleptoparasites may indirectly affect survival and reproduction of RCWs by preventing them from using cavities or impact reproduction directly by destroying nests (USFWS 2003). The impact of cavity kleptoparasites on RCW populations is a controversial issue. First, results of correlational (Conner et al. 1996; Kappes 2004) and experimental (Loeb and Hooper 1997; Mitchell et al. 1999; Laves and Loeb 1999; Walters et al. 2004) studies of these impacts are equivocal. Small but significant effects on reproduction or survival are found in some years in some populations, but no effects are found in other years and other populations. Second, even if there is an effect, often this will translate into an impact on the size of the non-breeder class rather than the number of suitable territories, and hence may have only a minimal effect on population growth (Walters 1991; Conner et al. 2001; Rudolph et al. 2004). However, reduced productivity may impact population growth when recruitment clusters are being employed to stimulate growth (see above), and any impacts on productivity are critical when populations are small and on the verge of extirpation (USFWS 2003).

The primary cavity kleptoparasite at SRS is the southern flying squirrel. Laves and Loeb (1999) removed flying squirrels from some clusters for two years and found that whole brood loss (but not partial brood loss) was reduced in clusters from which squirrels were removed compared to control clusters in one year, and partial brood loss (but not whole brood loss) was reduced in treated clusters in the second year. Removing squirrels from active clusters and recruitment clusters was part of the management strategy employed to rescue the SRS population from near extinction. From 1986 through 1994 on average 102 squirrels were removed from RCW cavities annually (Johnston 2005). During the period analyzed in our previous study 
(1995-1998) an average of 708 squirrels were removed annually (Johnston 2005) and during this period productivity was exceptionally high (see above). Thus there are reasons to believe that removing squirrels enhances RCW productivity, and thereby population growth, at SRS.

However, squirrel removal is a highly labor intensive management activity, and has become more so over time as the population (and number of RCW cavities) has increased. Because there is no feasible place to which to relocate the squirrels that are removed, they are killed, a procedure that is viewed negatively by much of the public. Passive control by equipping cavities with squirrel excluder devices (Montague et al. 1995) is not viewed as a viable option because the effectiveness of these devices is questionable (Edwards et al. 2000). In the past squirrel control has at times included repeated visits to RCW clusters and inspections of cavities to specifically check for squirrels. Removing squirrels as part of the cluster monitoring routine, that is removing them when encountered when checking cavities for RCW nests but not performing additional checks just for squirrels, represents a practicable level of flying squirrel control. Our objective was to determine whether this sustainable level of effort would produce significant benefits in terms of enhanced RCW productivity.

To achieve this objective, we divided clusters into two treatments, (1) those in which squirrels were removed when detected when cavities were checked for reproductive activity during monitoring visits (removal), and those in which any squirrels detected in cavities were allowed to remain (no removal or controls). We employed a stratified design, using type of cluster (active, experimental recruitment cluster, control recruitment cluster) and location (northern subpopulation, southern subpopulation) to define strata, and randomly assigned clusters to treatment group within strata. Response to treatment was measured during the breeding season, and response variables were various reproductive parameters.

We began the experiment in the 2002 breeding season and continued it for four years, through the 2005 breeding season. Random assignments of clusters to treatment groups within strata were redone each year, and thus different clusters received the removal treatment in different years, and a particular cluster received a different treatment in different years.

Our analysis is limited to effects of squirrel removal on productivity of occupied clusters: we did not assess effects of squirrel removal on occupation of recruitment clusters. The number of recruitment clusters included in the study varied from five in 2002 to nine in 2005, whereas the number of regular clusters varied from 36 to 40 . We used one-tailed statistical tests to test the hypothesis that reproduction was better in clusters in which squirrels were removed than in control clusters against the null hypothesis of no difference.

If squirrels interfere with reproduction by usurping cavities from the birds, the proportion of groups that nest should be higher and the proportion of nests that fail lower in treated clusters compared to control clusters. We found no evidence of either effect. Differences between treatments in the proportion of groups nesting were small, statistically insignificant and inconsistent in direction among years (Table 5). There were differences in nest failure rate that approached statistical significance in three of the four years, but in two of the three cases nest failure rates were lower in control clusters, not treated clusters (Table 5). In contrast there was evidence of an effect on partial brood loss as the number of young fledged per successful nest was higher in treated clusters in all four years, significantly so in two of the years (Table 5). However, overall productivity was significantly higher in treated clusters in only one of four years, and was virtually identical or slightly lower in the other three (Table 5). 
Table 5. Reproductive parameters for active RCW clusters in which any flying squirrels detected in cavities were removed (Removal) compared to clusters in which squirrels detected in cavities were allowed to remain (Control). Parameters are the proportion of active clusters containing groups (\% Groups), the proportion of groups that attempted nesting (\% Nesting), the proportion of first nesting attempts that failed (\% Nests Fail), number of young fledged per successful nest (Brood Size) and productivity measured as the number of fledglings produced per potential breeding group (Fledges/Group). * indicates statistically significant differences $(p<0.05$, onetailed test of hypothesis that parameter values are more favorable in Removal treatment). \# indicates marginally significant results $(p<0.15$, one-tailed test where Removal is more favorable, two-tailed test where Control is more favorable).

\begin{tabular}{|c|c|c|c|c|c|c|}
\hline & \% Groups & \% Nesting & \% Nests Fail & Brood Size & Fledges/Group & $\mathrm{N}$ \\
\hline $\mathbf{2 0 0 2}$ & & & & & & \\
\hline Removal & $95 \%$ & $75 \%$ & $27 \%$ & 2.25 & 1.35 & 21 \\
\hline Control & $100 \%$ & $86 \%$ & $29 \%$ & 2.21 & 1.57 & 21 \\
\hline $\mathbf{2 0 0 3}$ & & & & & & \\
\hline Removal & $83 \%$ & $89 \%$ & $12 \% \#$ & $2.25^{*}$ & $1.89 *$ & 23 \\
\hline Control & $91 \%$ & $85 \%$ & $29 \%$ & 1.77 & 1.15 & 22 \\
\hline $\mathbf{2 0 0 4}$ & & & & & & \\
\hline Removal & $95 \%$ & $90 \%$ & $26 \%$ & 2.44 & 1.86 & 22 \\
\hline Control & $91 \%$ & $85 \%$ & $6 \% \#$ & 2.31 & 1.85 & 22 \\
\hline $\mathbf{2 0 0 5}$ & & & & & & \\
\hline Removal & $91 \%$ & $90 \%$ & $17 \%$ & $2.40 *$ & 1.80 & 22 \\
\hline Control & $78 \%$ & $100 \%$ & $6 \% \#$ & 1.88 & 1.78 & 23 \\
\hline
\end{tabular}

The number of squirrels removed varied from 62-92 among years, which is many fewer than were removed during 1995-1998 (512-878). This presumably reflects primarily the less intensive method of squirrel control during this study, and secondarily the fact that only half of the clusters were treated, rather than variation in the size of the squirrel population or their use of RCW cavities. The practicable method of squirrel control tested thus resulted in removal of a small but significant number of squirrels, but did not consistently result in improved productivity in treated clusters. In most years the effort expended in removing squirrels produced no benefit to the population. Although it did produce a benefit in one year, the mechanism responsible for this benefit is unclear, making it impossible to predict in which years squirrel removal will be effective. The number of squirrels removed the year productivity was higher in treated cluster was modest (68). Whether a more intensive squirrel removal effort would be cost effective requires further experimentation, but the method we tested does not appear to be.

Our results beg further investigation of the nature of the interaction between squirrels and woodpeckers, which our results indicate to be more complex than what has been assumed. Flying squirrels evidently did not reduce productivity directly by destroying nests or occupying so many cavities that groups were unable to nest, but instead impacted the number of young fledged from a nest by indirect means. We reject the notion that squirrels might remove individual eggs or young as there are no reports of such behavior, nor did we observe any. Nor do we believe the effect on brood size to be an artifact as Laves and Loeb (1999) also found an effect on partial brood loss in one of the two years of their study. It is interesting that both the repeated, targeted squirrel trapping method employed by Laves and Loeb (1999) and the less intensive method we employed resulted in a partial brood loss effect, but only the former resulted 
in a whole brood loss effect. We can only speculate on the mechanism behind the effect of squirrel removal on partial brood loss. Possibilities include that adults are distracted by squirrels, reducing rates of feeding young or incubation constancy; that squirrels cause the birds to nest in inferior cavities that are less conducive to distributing food among young; that squirrels force some adults to roost in the open, thereby altering their energy budgets such that they reduce feeding rates to young; or that squirrels reduce food availability to woodpeckers somehow. We could list other hypotheses but all are as speculative and seemingly unlikely at these. The means by which squirrels might reduce RCW brood size remains a puzzle.

\section{Conclusions}

We conclude that recruitment clusters can be effective in stimulating growth of the SRS RCW population and that the strategy for placing recruitment clusters within $2 \mathrm{~km}$ of several existing woodpecker groups is sound. Recruitment clusters represent a highly cost effective management tool as they can make a large contribution to the bottom line of woodpecker management - population growth - yet require only a relatively modest management effort. In contrast, whether flying squirrel removal can be cost effective is questionable. The method of squirrel control we tested, which is sustainable in terms of labor, produced only modest management benefits which were inconsistent and unpredictable. We cannot recommend this method as a useful management tool. Whether a more intensive control method could produce sufficient benefits in enhanced RCW productivity to justify the greater effort and expense required to execute it, in a population as large as that at SRS, requires further testing. Although there might well be some benefit, and we believe increased productivity would result in enhanced population growth (see above), the size of the benefit likely will depend on the intensity of the control method. The repeated, targeted trapping employed by Laves and Loeb (1999) resulted in a benefit of 0.7 fledglings per group. We are skeptical that this level of effort population-wide could be sustainable, however, and therein lays the problem with this management element. Is there a level of effort that is practicable that can still produce a benefit? It appears that the answer may be no except in very small (i.e, < 30 groups, USFWS 2003) populations, and therefore managers might better devote time and funds to other activities.

\section{LIMITS TO RCW POPULATION GROWTH AT SRS}

The SRS RCW population was rescued from extirpation through intensive management that included importing birds from other populations (Franzreb 1997; Johnston 2005). Once the population reached 30 potential breeding groups in 2000, managers were expected to continue to recover the population without external augmentation (USFWS 2003). Recruitment cluster construction is the means to that end. The low rates of recruitment cluster occupation and low rates of transition of non-breeding birds to breeding status during our previous project suggested that at that time (i.e., the late 1990s) population growth might become limited by the ability of juveniles, helpers and floaters to locate recruitment clusters (Walters et al. 2001). The results of this project indicate that placing recruitment clusters within $2 \mathrm{~km}$ of multiple existing groups has removed this limitation. Yet population growth stagnated in 2004 and 2005. Low productivity during 2001-2003 contributed to this by reducing first the numbers of juveniles and subsequently the numbers of non-breeding helpers and floaters available to occupy recruitment clusters. We believe low productivity during these years was a stochastic event, and such environmental stochasticity does not represent a true limit to population growth, but rather a reality that will continue to cause population growth rate to be variable rather than constant. Growth should be 
assessed over the long term, as one expects a mix of years in which considerable gains in population size are made and years in which there is little or no growth.

However, over the course of the study we did observe one potential limit on population growth that is becoming increasingly important, availability of sufficient, suitable habitat to support recruitment clusters and associated new groups of woodpeckers. The RCW Recovery Plan requires that 49 ha of exclusive, high quality foraging habitat be provided for each group of birds (USFWS 2003). The common practice is to provide this habitat within a larger area assigned to a particular group, typically $80 \mathrm{ha}$, so that not every hectare of a group's allotment need qualify as high quality habitat at a given time. This allows managers more flexibility to provide for other land uses. Thus each group of RCWs, and each new recruitment cluster, must be allocated 80 ha of upland pine habitat, 49 ha of which is high quality habitat. At SRS much of the upland pine habitat appropriate for RCWs does not qualify as high quality foraging habitat because the overstory pines are too young and too dense, groundcover is not sufficiently grassy and diverse, and hardwood midstory is too extensive. Most of the habitat in the best condition is already claimed by existing groups of birds, and much of the remainder was assigned to new recruitment clusters during our study. It became progressively more difficult to identify locations with sufficient habitat in sufficiently good condition to support a new recruitment cluster as the study continued. In fact some of the sites used were marginal in this respect, and their relatively poor condition may well have contributed to the reduction in rate of occupation of recruitment clusters over the course of the study (Figure 5). That is, some of the recruitment clusters may have remained vacant not because no non-breeding birds located them, but because those birds that did locate them rejected them due to poor habitat quality. Supporting this notion is the observation that the only control clusters occupied were those with the very best habitat. We suspect that a habitat analysis would reveal a link between recruitment cluster occupancy and habitat condition during this study.

In the absence of further habitat management the problem of habitat availability will become more acute as the existing good sites are used up, leaving only poor sites for future recruitment cluster construction. We believe that shortage of high quality habitat will rapidly become the most important limitation to continued growth of the RCW population at SRS, if it has not already become so. Only time can increase the age of the young pine overstory, but dense overstory, excessive midstory and poor groundcover are larger problems that can be alleviated through management. Midstory and groundcover condition can be addressed by returning the most important natural driver, fire and most especially growing season fire, to the system (Christensen 1981; Hiers et al. 2000; Kirkman et al. 2004), and pine overstory can be thinned. Thus habitat restoration through prescribed burning, stand thinning and other techniques is the key to continued growth of the RCW population over the long term. Managers at SRS understand this and are actively using these management techniques to restore the conditions that describe high quality RCW foraging habitat (USFWS 2003). What we recommend is an intense habitat restoration program organized around the goal of establishing suitable habitat for future recruitment clusters at locations that are appropriate in space and time. Areas closest to existing population centers should be treated first as these will be the areas where recruitment clusters will be placed in the near future. Habitat improvements should work out from there in advance of the expansion of the population from the existing centers.

Toward the end of the study we identified potential locations for future recruitment clusters and devised initial management prescriptions for restoring habitat to a suitable condition in those locations. The product of this exercise was subsequently further developed by one of us 
(PJ) and it can serve as a road map for the intensive habitat restoration program required to support continued growth of the RCW population at SRS. A large number of potential future recruitment cluster locations were identified, and it is clear that the available suitable habitat at SRS, once restored to appropriate condition, can support a large population of RCWs in excess of the recovery goal of 250 potential breeding groups (USFWS 2003). Population growth at a rate of perhaps $5-10 \%$ per year toward the recovery goal is a reasonable objective for the RCW program at SRS.

\section{GRADUATE TRAINING ACCOMPLISHED}

Project funds supported one graduate student in the Department of Biological Sciences at Virginia Tech, T. Brandon Taylor, from the Fall 2001 semester through the Spring 2003 semester. Mr. Taylor successfully defended his thesis in February 2003 and received his Master of Science degree in May 2003. Mr. Taylor assisted SRS personnel in monitoring the RCW population in the 2002 breeding season, in addition to conducting his own research. Following Mr. Taylor's graduation project funds were used to pay additional graduate students in the avian ecology laboratory at Virginia Tech to assist in data management and analysis for the project.

In his thesis research, Mr. Taylor studied the relationship between the arthropod prey of RCWs on the boles of pine trees and the surrounding ground cover vegetation. Specifically, the goal of Mr. Taylor's research was to test one of the key assumptions of a hypothesis developed by Fran James and coworkers to explain correlations of productivity and size of RCW groups with the composition of the ground cover in their territories on the Apalachicola National Forest in Florida (James et al. 1997; 2001). That groups inhabiting territories with a relatively high proportion of forbs and grasses in the groundcover are larger and produce more young is now well established as a range-wide phenomenon (Walters et al. 2002a; USFWS 2003). James et al. $(1997 ; 2001)$ proposed that a high proportion of forbs and grasses in the groundcover reflects a history of frequent, growing-season fire, which results in increased abundance of arthropod prey for RCWs on the boles of pines. Greater availability of prey leads to improved foraging success, which in turn leads to increased productivity and larger groups. The relationship of groundcover to fire history is well established (Boyer 1990), and Hanula and Franzreb (1998) demonstrated that much of the prey taken by RCWs does indeed originate from the forest floor. That such prey is more abundant where the groundcover has a high proportion of grasses and forbs had not been demonstrated, however, and it is this assumption that Mr. Taylor tested.

Mr. Taylor sampled groundcover composition and arthropods on the boles of pines not only at SRS, but also at the nearby Fort Gordon Army Base across the Savannah River in Georgia, and at Camp Lejeune Marine Base in coastal North Carolina. Mr. Taylor indeed found that arthropod numbers and biomass were positively correlated with the proportion of grasses and forbs in the groundcover, and this relationship held at all three sites (Taylor 2003). He was thus able to confirm one of the key tenets of an important new hypothesis about foraging habitat quality for RCWs (Taylor and Walters 2004). For further details see Mr. Taylor's thesis (Taylor 2003) and a paper derived from it published in the last RCW symposium (Taylor and Walters 2004). Mr. Taylor's thesis was submitted to SRS previously as an additional product of this project.

\section{ACKNOWLEDGMENTS}

Funding for this project was provided by the Department of Energy-Savannah River Operations Office through the U.S. Forest Service Savannah River under Interagency Agreement DE-IA09-00SR22188. SRS is a National Environmental Research Park that provides an 
excellent atmosphere for conducting research. We are grateful to Forest Service personnel at SRS for many forms of assistance. In particular, John Blake has facilitated our work at SRS and supported the project in numerous ways. Paul Champlin assisted with fieldwork, and Beth LeMaster and Bill Jarvis contributed helpful discussions and logistical support.

\section{LITERATURE CITED}

Allen, D. H. 1991. An insert technique for constructing artificial red-cockaded woodpecker cavities. USDA Forest Service General Technical Report SE-73.

Allen, D. H., K. E. Franzreb and R. F. Escano. 1993. Efficacy of translocation strategies for red-cockaded woodpeckers. Wildlife Society Bulletin 21:155-159.

Beissinger, S. R. and M. I. Westphal. 1998. On the use of demographic models of population viability in endangered species management. Journal of Wildlife Management. 62:821841.

Boyer, W. D. 1990. Longleaf pine. Pages 405-412 in R. M. Burns and B. H. Honkala (eds.), Sylvics of North America. Volume 1. Conifers. USDA Agricultural Handbook 65, Washington, DC.

Brown, J. L. 1987. Helping and Communal Breeding in Birds: Ecology and Evolution. Princeton University Press, Princeton, NJ.

Carter, J. H., III, J. R. Walters, S. H. Everhart and P. D. Doerr. 1989. Restrictors for redcockaded woodpecker cavities. Wildlife Society Bulletin 17:68-72.

Christensen, N. L. 1981. Fire regimes in southeastern ecosystems. USDA Forest Service General Technical Report WO-26.

Conner, R. N. and D. C. Rudolph. 1989. Red-cockaded woodpecker colony status and trends on the Angelina, Davy Crockett, and Sabine National Forests. USDA Forest Service Research Paper SO-250.

Conner, R. N. and D. C. Rudolph. 1991. Forest habitat loss, fragmentation, and red-cockaded woodpecker populations. Wilson Bulletin 103:446-457.

Conner, R. N. and D. C. Rudolph. 1995. Excavation dynamics and use patterns of red-cockaded woodpecker cavities: relationships with cooperative breeding. Pages 343-352 in D. L. Kulhavy, R. G. Hooper and R. Costa (eds.), Red-cockaded Woodpecker: Recovery, Ecology and Management. Center for Applied Studies, College of Forestry, Stephen F. Austin State University, Nacogdoches, TX.

Conner, R. N., D. C. Rudolph, D. Saenz and R. R. Schaefer. 1996. Red-cockaded woodpecker nesting success, forest structure, and southern flying squirrels in Texas. Wilson Bulletin 108:697-711.

Conner, R. N., J. R. Walters and D. C. Rudolph. 2001. The Red-cockaded Woodpecker: Surviving in a Fire-Maintained Ecosystem. University of Texas Press, Austin, TX.

Copeyon, C. K. 1990. A technique for constructing cavities for the red-cockaded woodpecker. Wildlife Society Bulletin 18:303-311.

Copeyon, C. K., J. R. Walters and J. H. Carter, III. 1991. Induction of red-cockaded woodpecker group formation by artificial cavity construction. Journal of Wildlife Management 55:549-556.

Costa, R. and R. Escano. 1989. Red-cockaded woodpecker: status and management in the southern region in 1986. USDA Forest Service Technical Publication R8-TP12.

Daniels, S. J. 1997. Female Dispersal and Inbreeding in the Red-cockaded Woodpecker. M.S. thesis, Virginia Polytechnic Institute and State University, Blacksburg, VA. 
Daniels, S. J. and J. R. Walters. 2000a. Inbreeding depression and its effects on natal dispersal in red-cockaded woodpeckers. Condor 102:482-491.

Daniels, S. J. and J. R. Walters. 2000b. Between-year breeding dispersal in red-cockaded woodpeckers: multiple causes and estimated cost. Ecology 81:2473-2484.

DeFazio, J. T., Jr., M. A. Hunnicutt, M. R. Lennartz, G. L. Chapman and J. A. Jackson. 1987. Red-cockaded woodpecker translocation experiments in South Carolina. Proceedings of the Annual Conference of the Southeastern Association of Fish and Wildlife Agencies 41:311-317.

Doerr, P. D., J. R. Walters and J. H. Carter, III. 1989. Reoccupation of abandoned clusters of cavity trees (colonies) by red-cockaded woodpeckers. Proceedings of the Annual Conference of the Southeastern Association of Fish and Wildlife Agencies 43:326-336.

Edwards, J. W., W. M. Smathers, Jr., E. T. LeMaster and W. L. Jarvis. 2000. Savannah River Site red-cockaded woodpecker management plan. USDA Forest Service, Natural Resource Management and Research Institute. Unpublished report.

Epting, R. J., R. S. DeLotelle and T. Beaty. 1995. Red-cockaded woodpeckers territory and habitat use in Georgia and Florida. Pages 59-67 in D. L. Kulhavy, R. G. Hooper and R. Costa (eds.), Red-cockaded Woodpecker: Recovery, Ecology and Management. Center for Applied Studies, College of Forestry, Stephen F. Austin State University, Nacogdoches, TX.

Franzreb, K. E. 1997. Success of intensive management of a critically imperiled population of red-cockaded woodpeckers in South Carolina. Journal of Field Ornithology 68:458-470.

Frost, C. C., J. Walker and R. K. Peet. 1986. Fire-dependent savannas and prairies of the Southeast: original extent, preservation status and management. Pages 348-357 in D. L. Kulhavy and R. N. Conner (eds.), Wilderness and Natural Areas of the Eastern United States: a Management Challenge. Stephen F. Austin State University, Nacogdoches, TX.

Haig, S. M., J. R. Belthoff and D. H. Allen. 1993. Population viability analysis for a small population of red-cockaded woodpeckers and an evaluation of enhancement strategies. Conservation Biology 7:289-301.

Hanula J. L. and K. E. Franzreb. 1998. Source, distribution and abundance of macroarthropods on the bark of longleaf pine: potential prey of the red-cockaded woodpecker. Forest Ecology and Management 102:89-102.

Harding, S. R. and J. R. Walters. 2002. Processes regulating the population dynamics of redcockaded woodpecker cavities. Journal of Wildlife Management 66:1083-1095.

Harding, S. R. and J. R. Walters. 2004. Dynamics of cavity excavation by red-cockaded woodpeckers. Pages 412-422 in R. Costa and S. J. Daniels (eds.), Red-cockaded Woodpecker: Road to Recovery. Hancock House Publishing, Blaine, WA.

Heppell, S. S., J. R. Walters and L. B. Crowder. 1994. Evaluating management alternatives for red-cockaded woodpeckers: a modeling approach. Journal of Wildlife Management 58:479-487.

Heirs, J. K., R. Wyatt and R. J. Mitchell. 2000. The effects of fire regimes on legume reproduction in longleaf pine savannas: is a season selective? Oecologia 125:521-530.

Hooper, R. G. 1983. Colony formation by red-cockaded woodpeckers: hypotheses and management implications. Pages 72-77 in D. A. Wood (ed.), Red-cockaded Woodpecker Symposium II. Florida Game and Freshwater Fish Commission and U.S. Fish and Wildlife Service, Atlanta, GA. 
Hooper, R. G., D. L. Krusac and D. L. Carlson. 1991. An increase in a population of redcockaded woodpeckers. Wildlife Society Bulletin 19:277-286.

Jackson, J. A. 1978. Analysis of the distribution and population status of the red-cockaded woodpecker. Pages 101-111 in R. R. Odum and L. Landers (eds.), Proceedings of Rare and Endangered Wildlife Symposium. Georgia Department of Natural Resources, Game and Fish Division, Technical Bulletin W44.

Jackson, J. A. 1986. Biopolitics, management of federal lands, and the conservation of the redcockaded woodpecker. American Birds 40:1162-1168.

Jackson, J. A. 1990. Intercolony movements of red-cockaded woodpeckers in South Carolina. Journal of Field Ornithology 61:149-155.

Jackson, J. A. 1994. Red-cockaded woodpecker (Picoides borealis). In A. Poole and F. Gill (eds.), The birds of North America, No. 85. The Academy of Natural Sciences, Philadelphia, PA; The American Ornithologists' Union, Washington, DC.

James, F. C. 1995. The status of the red-cockaded woodpecker in 1990 and the prospect for recovery. Pages 439-451 in D. L. Kulhavy, R. G. Hooper and R. Costa (eds.), Redcockaded Woodpecker: Recovery, Ecology and Management. Center for Applied Studies, College of Forestry, Stephen F. Austin State University, Nacogdoches, TX.

James, F. C., C. A. Hess and D. Kufrin. 1997. Species-centered environmental analysis: indirect effects of fire history on red-cockaded woodpeckers. Ecological Applications 7:118-129.

James, F. C., C. A. Hess, B. C. Kicklighter and R. A. Thum. 2001. Ecosystem management and the niche gestalt of the red-cockaded woodpecker in longleaf pine forests. Ecological Applications 11:854-870.

Johnston, P. A. 2005. Red-cockaded woodpecker. Pages 301-312 in J. C. Kilgo and J. I. Blake (eds.), Ecology and Management of a Forested Landscape. Island Press, Washington, DC.

Kappes, J. J., Jr. 1997. Defining cavity-associated interactions between red-cockaded woodpeckers and other cavity-dependent species: interspecific competition or cavity kleptoparasitism? Auk 114:778-780.

Kappes, J. J., Jr. 2004. Community interactions associated with red-cockaded cavities. Pages 458-467 in R. Costa and S. J. Daniels (eds.), Red-cockaded Woodpecker: Road to Recovery. Hancock House Publishing, Blaine, WA.

Kirkman, L. K., P. C. Goebel, B. J. Palik and L. T. West. 2004. Predicting plant species diversity in a longleaf pine landscape. Ecoscience 11:80-93.

Laves, K. S. and S. C. Loeb. 1999. Effects of southern flying squirrels Glaucomys volans on red-cockaded woodpecker Picoides borealis reproductive success. Animal Conservation 2:295-303.

Lennartz, M., R. G. Hooper and R. F. Harlow. 1987. Sociality and cooperative breeding of red-cockaded woodpeckers, Picoides borealis. Behavioral Ecology and Sociobiology 20:77-88.

Letcher, B. H., J. A. Priddy, J. R. Walters and L. B. Crowder. 1998. An individual-based, spatially-explicit simulation model of the population dynamics of the endangered redcockaded woodpecker. Biological Conservation 86:1-14.

Ligon, J. D. 1970. Behavior and breeding biology of the red-cockaded woodpecker. Auk $87: 255-78$. 
Ligon, J. D., P. B. Stacey, R. N. Conner, C. E. Bock and C. S. Adkisson. 1986. Report of the American Ornithologists' Union Committee for the conservation of the red-cockaded woodpecker. Auk 103:848-855.

Loeb, S. C. and R. G. Hooper. 1997. An experimental test of interspecific competition for redcockaded woodpecker cavities. Journal of Wildlife Management 61:1268-1280.

Maguire, L. A., G. F. Wilhere and Q. Dong. 1995. Population viability analysis for red-cockaded woodpeckers in the Georgia Piedmont. Journal of Wildlife Management 59:533-542.

Mitchell, L. R., L. D. Carlile and C. R. Chandler. 1999. Effects of southern flying squirrels on nest success of red-cockaded woodpeckers. Journal of Wildlife Management 63:538-545.

Montague, W. G., J. C. Neal, J. E. Johnson and D. A. James. 1995. Techniques for excluding southern flying squirrels from cavities of red-cockaded woodpeckers. Pages 401-409 in D. L. Kulhavy, R. G. Hooper and R. Costa (eds.), Red-cockaded Woodpecker: Recovery, Ecology and Management. Center for Applied Studies in Forestry, College of Forestry, Stephen F. Austin State University, Nacogdoches, TX.

Perkins, J. L. 2006. Effects of Military Training Activity on Red-cockaded Woodpecker Demography and Behavior, and New Territory Formation in the Cooperatively Breeding Red-cockaded Woodpecker. M.S. thesis, Virginia Polytechnic Institute and State University, Blacksburg, VA.

Rudolph, D. C., R. N. Conner, D. K. Carrie and R. R. Shaefer. 1992. Experimental reintroduction of red-cockaded woodpeckers. Auk 109:914-916.

Rudolph, D. C., R. N. Conner and J. R. Walters. 2004. Red-cockaded woodpecker recovery: an integrated strategy. Pages 70-76 in R. Costa and S. J. Daniels (eds.), Red-cockaded Woodpecker: Road to Recovery. Hancock House Publishing, Blaine, WA.

Stacey, P. B. and J. D. Ligon. 1991. The benefits of philopatry hypothesis for the evolution of cooperative breeding: variation in territory quality and group size effects. American Naturalist 137:831-46.

Taylor T. B. 2003. Arthropod Assemblages on Longleaf Pines: a Possible Link Between the Red-cockaded Woodpecker and Groundcover Vegetation. M.S. thesis, Virginia Polytechnic Institute and State University, Blacksburg, VA.

Taylor, B. T. and J. R. Walters. 2004. Arthropod communities: a possible link between fire history and red-cockaded woodpeckers. Pages 653-656 in R. Costa and S. J. Daniels (eds.), Red-cockaded Woodpecker: Road to Recovery. Hancock House Publishing, Blaine, WA.

USDA. 1995. Final environmental impact statement for the management of the red-cockaded woodpecker and its habitat on national forests in the southeast region. Management Bulletin R8-MB 73, USDA Forest Service, Atlanta, GA.

U.S. Fish and Wildlife Service. 2003. Red-cockaded Woodpecker (Picoides borealis) Recovery Plan: Second Revision. U.S. Fish and Wildlife Service, Atlanta, GA.

Van Balen, J. B. and P. D. Doerr. 1978. The relationship of understory vegetation to redcockaded woodpecker activity. Proceedings of the Annual Conference of the Southeastern Association of Fish and Wildlife Agencies 32:82-92.

Walters, J. R. 1990. Red-cockaded woodpeckers: a "primitive" cooperative breeder. Pages 67-101 in Stacey, P. B. and W. D. Koenig (eds.), Cooperative Breeding in Birds: Long-Term Studies of Ecology and Behavior. Cambridge University Press, Cambridge, UK. 
Walters, J. R. 1991. Application of ecological principles to the management of endangered species: the case of the red-cockaded woodpecker. Annual Review of Ecology and Systematics 22:505-523.

Walters, J. R. 2004. Unusual dynamics in a rapidly increasing population of red-cockaded woodpeckers at Camp Lejeune, North Carolina. Pages 256-267 in R. Costa and S. J. Daniels (eds.), Red-cockaded Woodpecker: Road to Recovery. Hancock House Publishing, Blaine, WA.

Walters, J. R., P. D. Doerr and J. H. Carter, III. 1988. The cooperative breeding system of the red-cockaded woodpecker. Ethology 78:275-305.

Walters, J. R., P. D. Doerr and J. H. Carter, III. 1992a. Delayed dispersal and reproduction as a life history tactic in cooperative breeders: fitness calculations from red-cockaded woodpeckers. American Naturalist 139:623-643.

Walters, J. R., C. K. Copeyon and J. H. Carter, III. 1992b. Test of the ecological basis of cooperative breeding in red-cockaded woodpeckers. Auk 109:90-97.

Walters, J. R., J. H. Carter, III, P. D. Doerr and C. K. Copeyon. 1995. Response to drilled artificial cavities by red-cockaded woodpeckers in the North Carolina Sandhills: 4-year assessment. Pages 380-384 in D. L. Kulhavy, R. G. Hooper and R. Costa (eds.), Redcockaded Woodpecker: Recovery, Ecology and Management. Center for Applied Studies in Forestry, College of Forestry, Stephen F. Austin State University, Nacogdoches, TX.

Walters, J. R., T. B. Taylor, S. J. Daniels, L. B. Crowder and J. A. Priddy. 2001. Current and future dynamics of the red-cockaded woodpecker population inhabiting the Savannah River National Environmental Research Park: Managing for population growth. Unpublished report.

Walters, J. R., S.J. Daniels, J. H. Carter III and P. D. Doerr. 2002a. Defining quality of redcockaded woodpecker foraging habitat based on habitat use and fitness. Journal of Wildlife Management 66:1064-1082.

Walters, J. R., L. B. Crowder and J. A. Priddy. 2002b. Population viability analysis for redcockaded woodpeckers using an individual-based model. Ecological Applications 12:248-260.

Walters, J. R., T. B. Taylor, S. J. Daniels, L. B. Crowder and J. A. Priddy. 2003. An experimental study of the impact of location on the effectiveness of recruitment clusters for red-cockaded woodpeckers at the Savannah River Site: interim project report. Unpublished report.

Walters, J. R., K. E. Gault, B. W. Hagedorn, C. J. Petrick, L. F. Phillips. Jr., J. Tomcho, Jr. and A. Butler. 2004a. Effectiveness of recruitment clusters and intrapopulation translocation in promoting growth of the red-cockaded woodpecker population on Eglin Air Force Base, Florida. Pages 325-334 in R. Costa and S. J. Daniels (eds.), Red-cockaded Woodpecker: Road to Recovery. Hancock House Publishing, Blaine, WA.

Walters, J. R., J. H. Carter, III, and P. D. Doerr. 2004b. Population dynamics of red-cockaded woodpeckers and cavity kleptoparasites: implications of cavity experiments in the North Carolina Sandhills. Pages 468-479 in R. Costa and S. J. Daniels (eds.), Red-cockaded Woodpecker: Road to Recovery. Hancock House Publishing, Blaine, WA.

Ware, S., C. C. Frost and P. D. Doerr. 1993. Southern mixed hardwood forest: the former longleaf pine forests. Pages 447-493 in W. H. Martin, S. G. Boyce and A. C. Echternect (eds.), Biodiversity of the Southeastern United States. John Wiley and Sons, Inc., New York, NY. 